\title{
Share to Scare: Technology Sharing in the Absence of Intellectual Property Rights*
}

\author{
Jos Jansen \\ University of Cologne ${ }^{\dagger}$
}

January 2012

\begin{abstract}
I study the incentives of Cournot duopolists to share their technologies with their competitor in markets where intellectual property rights are absent and imitation is costless. The trade-off between a signaling effect and an expropriation effect determines the technology-sharing incentives. In equilibrium at most one firm shares some of its technologies. For similar technology distributions, there exists an equilibrium in which nobody shares. If the technology distributions are skewed towards efficient technologies, then there may exist equilibria in which one firm shares all technologies, only the best technologies, or only intermediate technologies. No other equilibria can exist.
\end{abstract}

Keywords: Cournot duopoly, strategic disclosure, indivisibility, innovation, trade secret, open source, skewed distribution JEL Codes: D82, L13, L17, O32, O34

*I thank Stefan Bechtold, Patrick Bolton, Jan Boone, Giacomo Calzolari, Ramon Faulí-Oller, David Gill, Maria Gil-Molto, Ela Glowicka, Georg von Graevenitz, Dietmar Harhoff, Martin Hellwig, Frédéric Koessler, Dan Kovenock, Gerard Llobet, Thomas Mertens, Andras Niedermayer, Martin Peitz, Joel Sandonis, Oz Shy, Philipp Weinschenk, seminar participants at the WZB (brown bag), EUI Microeconomics Research Workshop (Florence), MPI (Bonn), PSE (Paris), NHH (Bergen), University of Bologna, University of Erlangen-Nuremberg, UEA (Norwich), University of Cologne, University of Groningen, and attendees of the EARIE conference (Amsterdam), WZB conference on Antitrust and Innovation (Berlin), ASSET meeting (Padova), EEA Congress (Milan), 10th SFB/TR15 conference (Tutzing), ZEW conference on Economics of Innovation and Patenting (Mannheim), Industrial Organization Workshop (Otranto), and JEI (Valencia) for helpful discussions. I am grateful for the support of the WZB (Berlin), EUI (Florence), and MPI (Bonn) where part of the research for this paper was done. All errors are mine.

$\dagger$ Address: University of Cologne, Department of Economics, Chair Prof. Axel Ockenfels, Albertus-Magnus-Platz, D-50923 Cologne, Germany; E-mail <jos.jansen@wiso.uni-koeln.de> 


\section{Introduction}

The paper studies the incentives of profit-maximizing firms to freely reveal their process innovations to competitors. Upon disclosure the innovation is not protected by intellectual property rights, and the technology can be imitated at no cost. Such an analysis of disclosure incentives could be relevant in the context of less developed countries or transition economies, where institutions for the enforcement of intellectual property rights are weak or missing. ${ }^{1}$ This paper analyzes how firms should manage their intellectual property in such an environment.

An obvious strategy for a firm in an industry without intellectual property right protection would be to adopt secrecy. By adopting secrecy, a firm avoids imitation by its competitors, and maintains its potential technological lead. However, a secretive firm foregoes a potential benefit from sharing its technology. By sharing its technology, the firm persuades its competitors of the technology's efficiency, which may improve the firm's competitive position. The trade-off between the strategic gain from technology sharing and the loss from expropriation of the shared technology determines the incentive for technology sharing in my model.

The analysis could also provide insights in the strategic adoption of open source technology. There exists a growing literature on open source technology (see e.g. Harhoff et al., 2003, Lerner and Tirole, 2002, Maurer and Scotchmer, 2006, Von Hippel, 2005), where a number of important motives for the adoption of open source technologies by profit-maximizing firms is analyzed. For example, firms may generate revenues from activities that are complementary to the open source technology, they may adopt an open source technology to improve their market position through network externalities, or they may use an open source technology to signal their productivity. In this paper I explore some implications of the signaling motive for profit-maximizing firms. Also Blatter and Niedermayer (2008), Leppämäki and Mustonen (2009), and Spiegel (2009) analyze signaling motives for the adoption of open source projects. These papers focus on workers' signals to the labor market, whereas I analyze firms' signals to the product market. That is, I analyze a model where firms strategically manage their competitor's expectations by freely revealing their technology or keeping it secret. ${ }^{2}$

\footnotetext{
${ }^{1}$ Recent surveys in the US and EU suggest that, also in developed countries, patents are considerd to be less effective as a mechanism for appropriating the value of process innovations in comparison with secrecy (Levin et al., 1987, Cohen et al., 2000, and Arundel, 2001). My analysis can be seen as a limiting case in which patents are completely ineffective for the appropriation of value.

${ }^{2}$ In a recent survey, Henkel and Tins (2004) identify some motives that play a role in the decision
} 
Allen (1983) describes the case of technology sharing in the UK and US iron and steel industry of the 19th century. Firms in this industry received process innovations, through changes in the height and temperature of their blast furnaces, as a by-product of installing new production capacity. These productivity improvements were not patentable. In spite of the absence of intellectual property right protection, firms freely revealed process innovations by publications in engineering journals or through informal channels. Subsequently, the revealed innovations were adopted by competing firms. Finally, firms appear to be capacity-constrained and engaged in advancing size or output. The assumptions of my model (i.e., exogenous process innovations, no intellectual property protection, imitation of revealed technologies, and Cournot competition) seem to be consistent with the essential features of this case. ${ }^{3}$ I find conditions under which free revealing of technology can be an equilibrium strategy.

First, I find that the technology-sharing strategies are strategic substitutes. If one firm adopts a strategy in which some of the firm's technologies are shared, then the competitor adopts full secrecy in equilibrium. In other words, at most one firm shares some of its technology range. This result can be easily understood in the extreme situation in which a firm's competitor shares all technologies. In this case, the firm prefers to keep any technology secret, since the technology is either worse than average, or it would be expropriated with certainty if it were shared. The former is the case for technologies that are less or equally efficient than the competitor's technology, since imitation of the competitor's technology drives up the average efficiency of the firm's technology. For technologies that are more efficient than the competitor's technology, technology sharing would yield imitation, and the loss from certain expropriation would outweigh any potential gain from signaling.

Second, I find that the incentive to share a technology is strongest for intermediate cost values, i.e., the profit difference between disclosure and secrecy is hump-shaped. An increase of the efficiency level of a firm's technology increases the signaling gain at a constant rate, while the expropriation risk increases at an increasing rate. This gives an incentive to conceal "dramatic" news (i.e., extremely low and high costs), while

to freely reveal embedded Linux code by profit-maximizing firms. They report that $80 \%$ (respectively, $75 \%$ ) of the embedded Linux hardware (software) companies, participating in the survey, find the perception that "[c]ompeting companies use the code or learn from it, so there is a loss of competitive advantage" at least a somewhat important reason for not making their code public. This captures the loss from imitation. Moreover, Henkel and Tins find that $45.4 \%$ (respectively, $60.3 \%$ ) of the embedded Linux hardware (software) companies, participating in the survey, agreed that their company reveals code because "revealing good code improves [the] company's technical reputation," while 19.2\% $(8.6 \%)$ disagreed. This is consistent with the signaling motive.

${ }^{3}$ The incremental nature of innovations could be captured by a narrow technology space. 
sharing "anticipated" news. Recently, a few other papers analyze different economic problems with non-monotonic disclosure incentives (e.g., Board, 2009, Sun, 2011, and Jansen, 2010). Board (2009) and Sun (2011) study the incentives of firms to disclose information about their product characteristics to consumers. By contrast, I analyze a model in which firms disclose information about their technology to each other, not to a third party. Moreover, Board and Sun study symmetric distributions, whereas I also have results for skewed distributions. In fact, the skewness of technologies distributions plays a big role in my analysis. Jansen (2010) analyzes a model in which contestants try to influence the investment choices of a rival by disclosing information. Again, this economic model differs substantially from the model at hand.

These observations yield the following technology-sharing strategies in equilibrium. First, if the cost distributions are identical or similar, an equilibrium exists in which both firms conceal their technologies. By contrast, if distributions are sufficiently dissimilar, then such an equilibrium may not exist. Second, if the cost distribution of a firm's competitor is skewed towards efficient technologies, then the firm has an incentive to unilaterally share some technologies. Skewness limits the expected loss of expropriation, while the signaling gain remains. In this case, there always exists an equilibrium in which the firm shares all its technologies. Moreover, there may also exist an equilibrium in which one firm only shares its best technologies. Finally, an equilibrium may exist where one firm only shares intermediate technologies, while extreme technologies (and the rival's technology) are kept secret.

Endogenously, there may emerge market structures where profit-maximizing firms adopt different technology-sharing strategies. That is, firms with proprietary and open source technologies coexist in equilibrium despite the absence of intellectual property protection. Such an asymmetric equilibrium can emerge in a symmetric model as long as the technology distribution is not skewed towards inefficient technologies. In practice there are several examples of high-technology markets where freely revealing firms compete with concealing firms (see e.g. Moody, 2001). Llanes and De Elejalde (2009) also obtain the coexistence of proprietary and open source standards in equilibrium for profit-maximizing firms. Their analysis is complementary to mine, since they focus on investment spillovers and complementarities.

The paper contributes to the literature on strategic disclosure of verifiable information. Milgrom and Roberts (1986), and Okuno-Fujiwara et al. (1990) obtain an important "unraveling result." ${ }^{4}$ In the present paper, disclosure is costly, since a com-

\footnotetext{
${ }^{4}$ When it is known that the sender of information is informed, information is verifiable, and there
} 
petitor may imitate the technology, and become a more aggressive competitor. Consequently, the unraveling result may fail to hold. Also Anton and Yao (2003, 2004), Encaoua and Lefouili (2006), and Jansen (2006, 2011) study the strategic disclosure incentives of competing, innovative firms in the presence of knowledge spillovers. Anton and Yao, and Jansen study problems of one-sided asymmetric information. By contrast, I analyze a problem of two-sided asymmetric information here. In this way, I endogenize the identity of the disclosing firm. Further, with two-sided asymmetric information there remains uncertainty about the size of the knowledge spillover, which affects the technology-sharing incentives in an interesting way. ${ }^{5}$ In particular, there does not exist an equilibrium in which only technologies of intermediate productivity are shared in a model with one-sided asymmetric information (Jansen, 2010a), whereas such an equilibrium may exist with two-sided asymmetric information.

Gill (2008) studies a related model with two-sided asymmetric information. However, the present paper differs in some important ways from Gill. The analyses are complementary since Gill studies disclosure incentives in a model with discrete actions in the final stage (i.e., the decision whether to invest), while I study a model with a continuum of actions (i.e., output levels). Whereas Gill identifies conditions under which entry may be deterred by strategic disclosure, I characterize conditions under which accommodating firms disclose. There are some other notable differences between the two papers. First, in Gill the identity of the disclosing firm is exogenous (i.e., the leader). In the present paper both firms choose technology-sharing strategies simultaneously, and the identity of the disclosing firm is thereby determined endogenously. Second, Gill's model is tailored to competition in research and development, while I adopt a standard IO model of Cournot competition (although my model can also be interpreted as a static model of R\&D investment). Finally, the types in Gill's model are drawn from uniform distributions, while I do not impose such a restriction on the distributions of types. In fact, I show that the skewness of the technology distributions has important implications for a firm's incentives to share its technology.

The paper is organized as follows. The next section describes the model. The third section discusses the equilibrium output levels of firms for different technology-sharing choices. Section 4 derives the equilibrium technology-sharing strategies of firms. Sec-

are no costs of disclosure, then the sender often cannot do better than disclose his information, given skeptical equilibrium beliefs of the receiver.

${ }^{5}$ The present analysis differs in a second respect from Anton and Yao. They assume that innovations are infinitely divisible, and firms can choose to disclose only part of their technology. Encaoua and Lefouili, Jansen, and the present paper study indivisible innovations. In contrast to Anton and Yao's important results, I obtain equilibria that need not be fully revealing to firms. 
tion 5 gives implications for incentives to precommit to share technologies. Finally, section 6 concludes the paper. The Appendix contains all proofs of the propositions.

\section{The Model}

Two risk-neutral firms produce substitutable goods. The firms have private information about their costs of production, $\theta_{i}$ for firm $i$, with $i=1$, 2. Firm $i$ obtains a process innovation and has production cost $\theta_{i} \in \Theta$, with technology space $\Theta \equiv[\underline{\theta}, \bar{\theta}]$ for $0 \leq \underline{\theta}<\bar{\theta}$, and p.d.f. $f_{i}: \Theta \rightarrow \mathbb{R}_{+}$(and corresponding c.d.f. $F_{i}: \Theta \rightarrow[0,1]$ ) for $i=1,2$. There is full support, i.e. $f_{i}(\theta)>0$ for all $\theta \in \Theta$. The two firms' costs are independently distributed.

After each firm learns its cost, firms make technology-sharing choices. Firm $i$ with $\operatorname{cost} \theta_{i}$ chooses whether to reveal its technology truthfully, $s_{i}\left(\theta_{i}\right)=\theta_{i}$, or to keep its technology secret and send uninformative message $s_{i}\left(\theta_{i}\right)=\varnothing$. The technologysharing strategy of firm $i$ defines a partition $\left\{\mathcal{O}_{i}, \mathcal{S}_{i}\right\}$ of the technology space $\Theta$ (i.e., $\mathcal{O}_{i}, \mathcal{S}_{i} \subseteq \Theta$, with $\mathcal{O}_{i} \cap \mathcal{S}_{i}=\emptyset$ and $\left.\mathcal{O}_{i} \cup \mathcal{S}_{i}=\Theta\right)$ such that:

$$
s_{i}\left(\theta_{i}\right)= \begin{cases}\theta_{i}, & \text { if } \theta_{i} \in \mathcal{O}_{i} \\ \varnothing, & \text { if } \theta_{i} \in \mathcal{S}_{i} .\end{cases}
$$

In other words, $\mathcal{O}_{i}$ is the set with technologies that firm $i$ shares (i.e., technologies with an "open standard"), and $\mathcal{S}_{i}$ contains those technologies that firm $i$ keeps secret. Firms make their technology sharing decisions simultaneously.

Intellectual property rights for a shared technology do not exist. A firm's competitor can adopt a shared technology at no cost. Consequently, the competitor adopts the shared technology, if this technology enables the competitor to produce at a lower cost than his own technology. Therefore, firm $i$ has the following cost of production after technology sharing and adoption $(i, j \in\{1,2\}$ with $i \neq j)$ :

$$
c_{i}\left(\theta_{i}, s_{j}\right)= \begin{cases}\min \left\{\theta_{i}, \theta_{j}\right\}, & \text { if } s_{j}=\theta_{j} \\ \theta_{i}, & \text { if } s_{j}=\varnothing .\end{cases}
$$

The inverse demand for the good of firm $i$ is linear, i.e. $P_{i}(\mathbf{x})=\alpha-x_{i}-\beta x_{j}$, where $\mathbf{x} \equiv\left(x_{i}, x_{j}\right)$ is the bundle of outputs of firms $i$ and $j$, respectively, and $i, j \in\{1,2\}$ with $i \neq j$. I assume that the intercept $\alpha$ is sufficiently high to obtain interior solutions in the product market. Parameter $\beta$ represents the degree of product differentiation, with $0<\beta \leq 1 .^{6}$ After technologies are adopted, firms simultaneously choose their

\footnotetext{
${ }^{6}$ That is, I analyze a market for substitutable goods. If the goods were complementary (i.e., $\beta<0$ ), then the expropriation of a firm's technology would have a positive effect on the firm's profit. Consequently, there would be greater incentives to share technologies.
} 
output levels, $x_{i} \geq 0$ for firm $i$ with $i=1,2$ (Cournot competition). The profit of firm $i$ with $\operatorname{cost} c_{i}$ is (for $i, j \in\{1,2\}$ with $i \neq j$ ): ${ }^{7}$

$$
\pi_{i}\left(\mathbf{x} ; c_{i}\right)=\left(\alpha-c_{i}-x_{i}-\beta x_{j}\right) x_{i}
$$

I solve the game backwards in perfect Bayesian equilibria in pure strategies.

\section{Product Market Competition}

Three cases may emerge. First, I consider the situation where firms have complete information about their marginal costs of production. This situation emerges when both firms share their technologies: $\left(s_{i}, s_{j}\right)=\left(\theta_{i}, \theta_{j}\right)$. If the firms share marginal costs $\left(\theta_{i}, \theta_{j}\right)$, imitation gives each firm the efficient technology $\min \left\{\theta_{i}, \theta_{j}\right\}$. Consequently, firm $i$ supplies the following output in equilibrium (for $i, j \in\{1,2\}$ and $i \neq j$ ): ${ }^{8}$

$$
x_{i}^{o o}\left(\theta_{i}, \theta_{j}\right)=\frac{1}{2+\beta}\left(\alpha-\min \left\{\theta_{i}, \theta_{j}\right\}\right),
$$

Second, if firm $i$ shares $\theta_{i}$ and firm $j$ conceals, and firm $i$ has beliefs consistent with sharing strategy (2.1), then the first-order conditions of firms $i$ and $j$ are as follows (for $i, j \in\{1,2\}$ and $i \neq j$ ):

$$
2 x_{i}\left(\theta_{i}\right)=\alpha-\theta_{i}-\beta\left(\int_{\underline{\theta}}^{\theta_{i}} f_{j}\left(\theta \mid \theta_{j} \in \mathcal{S}_{j}\right) x_{j}(\theta) d \theta+\left[1-F_{j}\left(\theta_{i} \mid \theta_{j} \in \mathcal{S}_{j}\right)\right] x_{j}\left(\theta_{i}\right)\right)
$$

and

$$
2 x_{j}\left(\theta_{j}\right)=\alpha-\min \left\{\theta_{i}, \theta_{j}\right\}-\beta x_{i}\left(\theta_{i}\right),
$$

where $f_{j}\left(\cdot \mid \theta_{j} \in \mathcal{S}_{j}\right)$ and $F_{j}\left(\cdot \mid \theta_{j} \in \mathcal{S}_{j}\right)$ are respectively the posterior p.d.f. and c.d.f. for firm $j$ after concealment by this firm. These first-order conditions give the following

\footnotetext{
${ }^{7}$ The model can also be interpreted as a static model of winner-take-all R\&D competition in which firms choose whether to share their research designs. The investment level of firm $i, x_{i} \in$ $[0,1]$, determines the probability with which it makes an innovation. Firm $i$ 's cost of investment is $k \cdot\left(\theta_{i} x_{i}+x_{i}^{2}\right)$. If both firms innovate, each receives prize $T$. If only one firm innovates, the innovator receives prize $W$, with $0 \leq 2 T \leq W \leq k$. An unsuccessful firm receives no prize. Hence, firm $i$ 's expected profit is: $\pi_{i}\left(\mathbf{x} ; \theta_{i}\right)=\left[W-k \theta_{i}-k x_{i}-(W-T) x_{j}\right] x_{i}$. Normalization, i.e. $k=1$, and defining $W=\alpha$ and $W-T=\beta$, gives the profit function (2.3).

${ }^{8}$ In $x_{i}^{k l}(\cdot)$ the superscript $k \in\{o, s\}$ denotes whether firm $i$ adopted an open standard $(k=o)$ or adopted secrecy $(k=s)$. Similarly, superscript $l$ denotes whether firm $i$ 's competitor works under openess $(l=o)$ or secrecy $(l=s)$.
} 
equilibrium outputs (for $i, j \in\{1,2\}$ and $i \neq j$ ):

$$
\begin{aligned}
x_{i}^{o s}\left(\theta_{i} ; \mathcal{S}_{j}\right)= & \frac{1}{4-\beta^{2}}\left((2-\beta) \alpha-2 \theta_{i}+\beta E_{j}\left(\min \left\{\theta_{i}, \theta_{j}\right\} \mid \theta_{j} \in \mathcal{S}_{j}\right)\right), \\
x_{j}^{s o}\left(\theta_{j}, \theta_{i} ; \mathcal{S}_{j}\right)= & \frac{1}{4-\beta^{2}}\left((2-\beta) \alpha-2 \min \left\{\theta_{i}, \theta_{j}\right\}+\beta \theta_{i}\right. \\
& \left.+\frac{\beta^{2}}{2}\left[\min \left\{\theta_{i}, \theta_{j}\right\}-E_{j}\left(\min \left\{\theta_{i}, \theta_{j}\right\} \mid \theta_{j} \in \mathcal{S}_{j}\right)\right]\right),
\end{aligned}
$$

where

$E_{j}\left(\min \left\{\theta_{i}, \theta_{j}\right\} \mid \theta_{j} \in \mathcal{S}_{j}\right)=F_{j}\left(\theta_{i} \mid \theta_{j} \in \mathcal{S}_{j}\right) E\left\{\theta_{j} \mid \theta_{j} \leq \theta_{i}, \theta_{j} \in \mathcal{S}_{j}\right\}+\left[1-F_{j}\left(\theta_{i} \mid \theta_{j} \in \mathcal{S}_{j}\right)\right] \theta_{i}$

and

$$
E\left\{\theta_{j} \mid \theta_{j} \leq \theta_{i}, \theta_{j} \in \mathcal{S}_{j}\right\}=\int_{\underline{\theta}}^{\theta_{i}} \frac{f_{j}\left(\theta \mid \theta_{j} \in \mathcal{S}_{j}\right)}{F_{j}\left(\theta_{i} \mid \theta_{j} \in \mathcal{S}_{j}\right)} \theta d \theta .
$$

Finally, in the remaining case, where both firms choose secrecy, $\left(s_{i}, s_{j}\right)=(\varnothing, \varnothing)$, profit maximization gives the following first-order condition for firm $i$ :

$$
2 x_{i}\left(\theta_{i}\right)=\alpha-\theta_{i}-\beta E\left\{x_{j}\left(\theta_{j}\right) \mid \theta_{j} \in \mathcal{S}_{j}\right\}
$$

where $E\left\{\theta_{j} \mid \theta_{j} \in \mathcal{S}_{j}\right\}$ is firm $j$ 's expected cost conditional on concealment by firm $j$. Solving for the equilibrium gives the following output level for firm $i(i, j \in\{1,2\}$ and $i \neq j)$ :

$x_{i}^{s s}\left(\theta_{i} ; \mathcal{S}_{i}, \mathcal{S}_{j}\right)=\frac{1}{4-\beta^{2}}\left((2-\beta) \alpha-2 \theta_{i}+\beta E\left\{\theta_{j} \mid \theta_{j} \in \mathcal{S}_{j}\right\}+\frac{\beta^{2}}{2}\left[\theta_{i}-E\left\{\theta_{i} \mid \theta_{i} \in \mathcal{S}_{i}\right\}\right]\right)$.

In any situation the expected equilibrium product market profit is: $\pi_{i}^{k l}(\cdot)=x_{i}^{k l}(\cdot)^{2}$ with $k, l \in\{o, s\}$ and $i=1,2$.

\section{Technology Sharing Strategies}

In this section I characterize the firms' interim incentives to share technologies.

\subsection{Basic Properties of Equilibrium Strategies}

A firm's technology-sharing strategy follows from comparing the firm's expected profit under sharing with the expected profit under secrecy. Suppose firm $i$ 's beliefs about its competitor's technology-sharing strategy are consistent with the partition $\left\{\mathcal{O}_{j}, \mathcal{S}_{j}\right\}$ 
for $i, j \in\{1,2\}$ with $i \neq j$, and firm $j$ 's technology-sharing strategy gives the partition $\left\{\mathcal{O}_{j}, \mathcal{S}_{j}\right\}$ of the set $\Theta$. Given these assumptions, firm $i$ 's expected profit from technology-sharing and secrecy are, respectively:

$$
\begin{aligned}
\Pi_{i}^{o}\left(\theta_{i} ; \mathcal{S}_{j}\right) & \equiv \int_{\theta_{j} \in \mathcal{O}_{j}} \pi_{i}^{o o}\left(\theta_{i}, \theta_{j}\right) d F_{j}\left(\theta_{j}\right)+\int_{\theta_{j} \in \mathcal{S}_{j}} \pi_{i}^{o s}\left(\theta_{i} ; \mathcal{S}_{j}\right) d F_{j}\left(\theta_{j}\right) \\
\Pi_{i}^{s}\left(\theta_{i} ; \mathcal{S}_{i}, \mathcal{S}_{j}\right) & \equiv \int_{\theta_{j} \in \mathcal{O}_{j}} \pi_{i}^{s o}\left(\theta_{i}, \theta_{j} ; \mathcal{S}_{i}\right) d F_{j}\left(\theta_{j}\right)+\int_{\theta_{j} \in \mathcal{S}_{j}} \pi_{i}^{s s}\left(\theta_{i} ; \mathcal{S}_{i}, \mathcal{S}_{j}\right) d F_{j}\left(\theta_{j}\right) .
\end{aligned}
$$

Hence, the difference of the expected profit from technology sharing and secrecy is:

$$
\begin{aligned}
\Psi\left(\theta_{i} ; \mathcal{S}_{i}, \mathcal{S}_{j}\right) \equiv & \Pi_{i}^{o}\left(\theta_{i} ; \mathcal{S}_{i}\right)-\Pi_{i}^{s}\left(\theta_{i} ; \mathcal{S}_{i}, \mathcal{S}_{j}\right) \\
= & \int_{\theta_{j} \in \mathcal{O}_{j}}\left[x_{i}^{o o}\left(\theta_{i}, \theta_{j}\right)^{2}-x_{i}^{s o}\left(\theta_{i}, \theta_{j} ; \mathcal{S}_{i}\right)^{2}\right] d F_{j}\left(\theta_{j}\right) \\
& \quad+\operatorname{Pr}\left[\theta_{j} \in \mathcal{S}_{j}\right]\left[x_{i}^{o s}\left(\theta_{i} ; \mathcal{S}_{j}\right)^{2}-x_{i}^{s s}\left(\theta_{i} ; \mathcal{S}_{i}, \mathcal{S}_{j}\right)^{2}\right]
\end{aligned}
$$

The comparison between $x_{i}^{o o}\left(\theta_{i}, \theta_{j}\right)$ and $x_{i}^{s o}\left(\theta_{i}, \theta_{j} ; \mathcal{S}_{i}\right)$ gives the following trade-off. On the one hand, sharing the technology $\theta_{i}$ enables the firm's competitor to imitate the technology and become a more "aggressive" output-setter, whereas secrecy gives no expropriation. That is, after technology sharing the competitor gets marginal cost $\min \left\{\theta_{i}, \theta_{j}\right\}$ instead of $\theta_{j}$. On the other hand, by sharing technology $\theta_{i}$, firm $i$ informs its competitor about firm $i$ 's actual marginal cost (i.e., $\min \left\{\theta_{i}, \theta_{j}\right\}$ ), which enables the competitor to adjust his output levels accordingly. By contrast, secrecy forces the competitor to set an output level as a best response against firm $i$ with an average marginal cost (i.e., $\left.E_{i}\left(\min \left\{\theta_{i}, \theta_{j}\right\} \mid \theta_{i} \in \mathcal{S}_{i}\right)\right)$. This explains the last term of $x_{i}^{s o}\left(\theta_{i}, \theta_{j} ; \mathcal{S}_{i}\right)$, which gives a signaling effect. Comparing $x_{i}^{o s}\left(\theta_{i} ; \mathcal{S}_{j}\right)$ with $x_{i}^{s s}\left(\theta_{i} ; \mathcal{S}_{i}, \mathcal{S}_{j}\right)$ gives a similar trade-off.

A firm with a sufficiently inefficient technology has a disincentive to share its technology since the signaling and expropriation effects reinforce each other. A firm that would share an inefficient technology risks expropriation by its competitor, and signals to its competitor that it will be a "soft" competitor in the product market. Both effects make the competitor an "aggressive" output-setter (strategic substitutes), which lowers the profit of the firm. This observation gives the following negative result.

Proposition 1 For any $i=1,2$, and $\underline{\theta}<l<\bar{\theta}$, there exists no equilibrium in which firm $i$ chooses technology-sharing strategy $s_{i}$ with $\mathcal{O}_{i}=[l, \bar{\theta}]$.

A firm with an efficient technology faces trade-off between two conflicting effects. On the one hand, the firm's competitor may imitate the disclosed technology and 
thereby become a more "aggressive" competitor in the product market. This expropriation effect gives the firm a disincentive to share the technology. On the other hand, the firm demonstrates it will be an "aggressive" competitor in the product market which reduces the output supplied by its competitor (strategic substitutes). This signaling effect gives the firm an incentive to share the technology.

The incentive to share a technology also depends on the competitor's technologysharing strategy. The following proposition suggests that the technology-sharing strategies are strategic substitutes.

Proposition 2 There exists no equilibrium in which both firms share some technologies, i.e., if firm $i$ chooses strategy $s_{i}$ with $\mathcal{O}_{i} \neq \emptyset$ in equilibrium, then firm $j$ chooses strategy $s_{j}$ with $\mathcal{O}_{j}=\emptyset$ in equilibrium for $i, j \in\{1,2\}$ and $i \neq j$.

First, in those instances where firm $i$ shares its technology (i.e., for $\theta_{i} \in \mathcal{O}_{i}$ ), firm $j$ has a disincentive to share. If firm $i$ shares its technology, $\theta_{i}$, then firm $i$ knows that its competitor has a technology which is at least as good as $\theta_{i}$. As a consequence, the competitor (firm $j$ ) has no incentive to share a technology which is less efficient than $\theta_{i}$, since firm $j$ would thereby signal that it is less efficient than expected (i.e., $\left.\theta_{i} \geq E_{j}\left(\min \left\{\theta_{i}, \theta_{j}\right\} \mid \theta_{j} \in \mathcal{S}_{j}\right)\right)$. Furthermore, if the competitor would share a technology which is more efficient than $\theta_{i}$, then the technology will be imitated with certainty. In this case, the direct effect of expropriation with certainty outweighs the indirect effect from signaling. This observation is consistent with previous results in models with one-sided asymmetric information (e.g., Anton and Yao, 2003-4, and Jansen, 2006, 2011), where the expropriation effect dominates the signaling effect in the absence of intellectual property rights.

Second, in those instances where firm $i$ does not share (i.e., for $\theta_{i} \in \mathcal{S}_{i}$ with $\mathcal{S}_{i} \neq \Theta$ ), the argument is a little more subtle. The fact that firm $i$ has an incentive to share some technologies implies that the competitor's posterior distribution must be relatively more skewed towards efficient technologies compared to firm $i$ 's distribution. ${ }^{9}$ Only in this case does firm $i$ 's sharing of an efficient technology give a relatively low risk of imitation (weak expropriation effect), and a drastic update of firm $j$ 's beliefs after sharing the technology (strong signaling effect). Whereas this situation gives firm $i$ an incentive to share some technologies, it gives a disincentive to firm $i$ 's competitor. It implies that the competitor is in a position where technology sharing yields a relatively strong expropriation effect and weak signaling effect.

\footnotetext{
${ }^{9}$ For example, it is straightforward to show that, if firm $i$ has an incentive to share some technologies, then $E\left\{\theta_{j} \mid \theta_{j} \in \mathcal{S}_{j}\right\}<E\left\{\theta_{i} \mid \theta_{i} \in \mathcal{S}_{i}\right\}$ for $i, j \in\{1,2\}$ and $i \neq j$.
} 
Proposition 2 shows that the competitor's expropriation effect always outweighs the signaling effect in this situation.

\subsection{Equilibrium Strategies}

This section discusses a firm's incentive to unilaterally share its technology, given full concealment by the firm's competitor (i.e., $\mathcal{S}_{j}=\Theta$ ). Proposition 2 shows that this restriction does not exclude any equilibrium.

Firm $i$ receives the profit of $x_{i}^{o s}\left(\theta_{i} ; \Theta\right)^{2}$ from sharing its technology $\theta_{i}$ when its competitor conceals all technologies. ${ }^{10}$ The firm earns the profit $x_{i}^{s s}\left(\theta_{i} ; \mathcal{S}_{i}, \Theta\right)^{2}$ if the firm conceals its cost and its competitor conceals all costs. ${ }^{11}$ Firm $i$ has an incentive to share its technology $\theta_{i}$ if $x_{i}^{o s}\left(\theta_{i} ; \Theta\right) \geq x_{i}^{s s}\left(\theta_{i} ; \mathcal{S}_{i}, \Theta\right)$, which reduces to $\psi_{i}\left(\theta_{i} ; \mathcal{S}_{i}\right) \geq 0$, where:

$$
\psi_{i}\left(\theta_{i} ; \mathcal{S}_{i}\right) \equiv-\left[1-F_{j}\left(\theta_{i}\right)\right]\left(E\left\{\theta_{j} \mid \theta_{j} \geq \theta_{i}\right\}-\theta_{i}\right)+\frac{\beta}{2}\left[E\left\{\theta_{i} \mid \theta_{i} \in \mathcal{S}_{i}\right\}-\theta_{i}\right] .
$$

The two terms in function $\psi_{i}$ reflect the trade-off between the expropriation effect and the signaling effect.

The first term of $\psi_{i}$ represents the expropriation effect. This effect captures the effect of a firm's technology-sharing decision on its rival's marginal cost in the product market. Technology sharing has only an effect on the competitor's marginal cost if the competitor chooses to imitate the technology. Imitation only occurs if the competitor is less efficient, which happens with probability $1-F_{j}\left(\theta_{i}\right)$. In that case, firm $i$ 's competitor produces at unit $\operatorname{cost} \theta_{i}$ after sharing by firm $i$. On the other hand, if firm $i$ conceals its technology to a less efficient competitor, then the expected cost of the competitor equals $E\left\{\theta_{j} \mid \theta_{j} \geq \theta_{i}\right\}$. Hence, the first term of expression (4.4) is the difference between the expected cost of a competitor after technology sharing with subsequent imitation, and concealment. It thereby captures the expected loss from expropriation.

The second term of $\psi_{i}$ gives the signaling effect of technology sharing. It captures the effect of firm $i$ 's technology-sharing decision on its competitor's output through the competitor's perception of firm $i$ 's cost. After firm $i$ shares technology $\theta_{i}$, the competitor knows that he competes with a firm with cost level $\theta_{i}$ instead of the average cost level $E\left\{\theta_{i} \mid \theta_{i} \in \mathcal{S}_{i}\right\}$. The effect of this update of beliefs on firm $j$ 's

\footnotetext{
${ }^{10}$ Output $x_{i}^{o s}$ is defined in (3.4) with $E_{j}\left(\min \left\{\theta_{i}, \theta_{j}\right\} \mid \theta_{j} \in \Theta\right)=F_{j}\left(\theta_{i}\right) E\left\{\theta_{j} \mid \theta_{j} \leq \theta_{i}\right\}+\left[1-F_{j}\left(\theta_{i}\right)\right] \theta_{i}$.

${ }^{11}$ Here $x_{i}^{s s}$ is as in (3.7) with $E\left(\theta_{j} \mid \theta_{j} \in \mathcal{S}_{j}\right)=E\left(\theta_{j}\right)$ and $E\left(\theta_{i} \mid \theta_{i} \in \mathcal{S}_{i}\right)$ is consistent with firm $i$ 's technology-sharing strategy.
} 
output depends on the responsiveness of firm $j$ 's best response function towards firm i's outputs $(\beta / 2)$.

The overall effect of a marginal increase of $\theta_{i}$ is as follows:

$$
\psi_{i}^{\prime}\left(\theta_{i} ; \cdot\right)=\left[1-F_{j}\left(\theta_{i}\right)\right]-\frac{\beta}{2} .
$$

That is, an increase of $\theta_{i}$ makes both effects weaker. The expropriation effect becomes weaker since it becomes less likely that the competitor imitates the firm's technology (i.e., the first term of (4.4) is negative and increasing in $\theta_{i}$ ). The signaling effect also becomes weaker after a cost increase since the firm becomes a less "aggressive" output supplier in the product market, which enables it to steal a smaller share of the market from its competitor (i.e., the second term in (4.4) is initially positive but subsequently negative, and decreasing in firm $i$ 's marginal cost).

The function $\psi_{i}$ is strictly concave in cost $\theta_{i}$, i.e., $\psi_{i}^{\prime \prime}\left(\theta_{i} ; \cdot\right)=-f_{j}\left(\theta_{i}\right)<0$ for all $\theta_{i}$. An increase of $\theta_{i}$ weakens the expropriation and signaling effects at different rates. The rate at which the expropriation effect becomes weaker is proportional to the probability of expropriation. This probability is decreasing in the cost level $\theta_{i}$. The signaling effect becomes weaker at a constant rate. This rate is initially smaller than the rate of change of expropriation, since the signaling effect is an indirect effect. Therefore, the incentive to share a technology is growing for low $\theta_{i}$. Eventually, the signaling effect becomes aligned with the expropriation effect and grows in $\theta_{i}$ at a constant rate. The expropriation effect weakens at a diminishing rate. This gives a growing disincentive to share technologies for high $\theta_{i}$. This implies the following.

Proposition 3 In any equilibrium there are some bounds $l_{i}, h_{i} \in \Theta$, with $l_{i} \leq h_{i}$, such that firm $i$ chooses technology-sharing strategy $s_{i}$ with $\mathcal{O}_{i}=\left[l_{i}, h_{i}\right]$, for $i=1,2$.

Hence, in equilibrium shared technologies have to form a single interval. ${ }^{12}$ The sign of $\psi_{i}^{\prime}\left(\theta_{i} ; \cdot\right)$ depends on the size of the cost $\theta_{i}$. In particular, $\psi_{i}^{\prime}(\underline{\theta} ; \cdot)=1-\frac{\beta}{2}>0$ and $\psi_{i}^{\prime}(\bar{\theta} ; \cdot)=-\frac{\beta}{2}<0$. The function $\psi_{i}$ reaches a maximum for the marginal cost:

$$
\widehat{\theta}_{i} \equiv F_{j}^{-1}(1-\beta / 2)
$$

For example, if goods are homogeneous (i.e., $\beta=1$ ), then $\psi_{i}$ reaches a maximum when $\theta_{i}$ equals the median cost of firm $j$. Hence, firm $i$ 's incentive to unilaterally share its technology is strongest for an intermediate cost level, i.e., $\theta_{i}=\widehat{\theta}_{i}$.

\footnotetext{
${ }^{12}$ Lemma 1 in the proof of Proposition 2 shows that this property does not rely on the assumption that the competitor conceals all technologies, since it holds for any strategy of the competitor.
} 
These observations have immediate consequences for the equilibrium technologysharing strategies. Propositions 1-3 imply that there can be at most four kinds of technology-sharing strategies in equilibrium: both firms share nothing, one firm shares all technologies, one firm shares only the best technologies, or one firm shares only intermediate technologies. The analysis below characterizes under what conditions these equilibria emerge.

\subsubsection{Share Nothing}

First, I characterize the conditions under which firms conceal all technologies in equilibrium. Suppose both firms conceal all their technologies (i.e., $\mathcal{S}_{1}=\mathcal{S}_{2}=\Theta$ ), and the firms have beliefs consistent with full concealment. Consequently, firm $i$ 's competitor expects cost $E\left(\theta_{i}\right)$ of firm $i$ after concealment. Hence, firm $i$ has no incentive to deviate unilaterally from full concealment by sharing the technology $\theta_{i}$, if $\psi_{i}\left(\theta_{i} ; \Theta\right) \leq 0$ for all $\theta_{i} \in \Theta$, with $\psi_{i}$ as in (4.4). A necessary and sufficient condition for the emergence of full concealment in equilibrium is therefore: $\psi_{i}\left(\widehat{\theta}_{i} ; \Theta\right) \leq 0$ for $i=1,2$. This condition reduces to the following (for $i, j \in\{1,2\}$ and $i \neq j$ ):

$$
E\left\{\theta_{j} \mid \theta_{j} \geq \widehat{\theta}_{i}\right\} \geq E\left(\theta_{i}\right)
$$

I summarize the analysis in the following proposition.

Proposition 4 There exists an equilibrium where both firms conceal all technologies (i.e., $\mathcal{S}_{1}=\mathcal{S}_{2}=\Theta$ ) if and only if condition $\left(C_{S}\right)$ holds for $i, j \in\{1,2\}$ and $i \neq j$, with $\widehat{\theta}_{i}$ as defined in (4.6).

It is immediate that the condition is satisfied if the firms' cost distributions have equal means, i.e. $E\left(\theta_{i}\right)=E\left(\theta_{j}\right) \cdot{ }^{13}$ Moreover, the condition cannot be violated for more than one of the firms.

Condition $\left(\mathrm{C}_{S}\right)$ is violated whenever the firms' technology distributions are sufficiently dissimilar. For example, if the distribution of firm $i$ 's technology parameters is skewed towards inefficient technologies, while firm $j$ 's distribution is non-skewed or skewed towards efficient technologies. In such a situation firm $i$ with technology $\widehat{\theta}_{i}$ has an incentive to unilaterally share its technology. Sharing the technology $\widehat{\theta}_{i}$ has only a limited expropriation effect, since the average efficiency of the competitor's technology does not differ much from $\widehat{\theta}_{i}$. However, technology sharing has a substantial signaling

\footnotetext{
${ }^{13}$ In that case, the condition holds, since $E\left\{\theta_{j} \mid \theta_{j} \geq \widehat{\theta}_{i}\right\} \geq E\left(\theta_{j}\right)=E\left(\theta_{i}\right)$.
} 
effect. Technology $\widehat{\theta}_{i}$ is far more efficient than firm $i$ 's average technology if firm $i$ 's prior distribution is skewed towards inefficient technologies. Therefore, sharing technology $\widehat{\theta}_{i}$ yields a drastic update of firm $j$ 's beliefs about firm $i$ 's efficiency, and a downward adjustment of firm $j$ 's average output level.

An increase of the product substitutability, $\beta$, strengthens the signaling effect, which weakens a firm's incentive to keep its technology secret. This is reflected by the fact that condition $\left(\mathrm{C}_{S}\right)$ becomes more stringent after an increase of $\beta$, since $\widehat{\theta}_{i}$ is decreasing in $\beta$.

\subsubsection{Share All Technologies}

Now I study firm $i$ 's incentives to share all its cost information, i.e., $\mathcal{O}_{i}=\Theta$, given that firm $j$ conceals all. Again, I can use function $\psi_{i}$ in (4.4) to analyze firm $i$ 's technology-sharing incentives in equilibrium. The beliefs of firm $i$ 's competitor that are consistent with full sharing by firm $i$ are skeptical beliefs, i.e., $E\left(\theta_{i} \mid \theta_{i} \in \mathcal{S}_{i}\right)=\bar{\theta}$ or $\mathcal{S}_{i}=\{\bar{\theta}\}$. Firm $i$ has no incentive to conceal information, given skeptical beliefs, if $\psi_{i}\left(\theta_{i} ;\{\bar{\theta}\}\right) \geq 0$ for all $\theta_{i}$. Concavity of $\psi_{i}$ in $\theta_{i}$ reduces the equilibrium condition to $\psi_{i}(\underline{\theta} ;\{\bar{\theta}\}) \geq 0$, which is satisfied if and only if:

$$
E\left(\theta_{j}\right) \leq\left(1-\frac{\beta}{2}\right) \underline{\theta}+\frac{\beta}{2} \bar{\theta} .
$$

The following proposition states this result formally.

Proposition 5 There exists an equilibrium where firm $i$ shares all technologies while firm $j$ conceals all technologies (i.e., $\mathcal{S}_{i}=\{\bar{\theta}\}$ and $\mathcal{S}_{j}=\Theta$ ) if and only if condition $\left(C_{O}\right)$ holds.

Hence, firm $i$ has an incentive to share all technologies if firm $j$ 's average cost is sufficiently low, and firm $j$ conceals its technologies. In this case, firm $i$ with the most efficient technology (i.e., $\theta_{i}=\underline{\theta}$ ) would create only a marginally more efficient competitor by sharing its technology. However, technology sharing changes the competitor's beliefs dramatically: from the least efficient technology (after concealment) to the most efficient (after sharing). This puts firm $i$ in an advantageous strategic position. Therefore, under condition $\left(\mathrm{C}_{O}\right)$ the signaling effect dominates for firm $i$.

Notice that condition $\left(\mathrm{C}_{O}\right)$ does not require asymmetry between firms, since it can hold in a symmetric model (i.e., $\left.E\left(\theta_{1}\right)=E\left(\theta_{2}\right) \leq\left(1-\frac{\beta}{2}\right) \underline{\theta}+\frac{\beta}{2} \bar{\theta}\right)$. The condition only requires that a competitor's technology distribution is not skewed towards inefficient technologies. 
Increasing the degree of product substitutability $(\beta)$ increases the relative strength of the signaling effect, and gives a stronger incentive to share technologies. Therefore, condition $\left(\mathrm{C}_{O}\right)$ becomes weaker. For example, at the extreme where goods are homogeneous (i.e., $\beta=1$ ) an equilibrium with full sharing can already emerge for technology distributions that are symmetric on the interval $\Theta$ (i.e., $E\left(\theta_{j}\right)=\frac{1}{2}(\underline{\theta}+\bar{\theta})$ ).

\subsubsection{Share Only The Best Technologies}

So far, I presented equilibria in which firms choose strategies that do not depend on their technology draw. In this subsection I discuss the incentives to share selectively. In particular, I give conditions for the existence of an equilibrium in which a firm shares its best technologies while all other technologies are kept secret. It is necessary and sufficient that there exist some $h$, with $\widehat{\theta}_{i}<h<\bar{\theta}$, such that:

$$
\psi_{i}(h ;[h, \bar{\theta}])=0 \text { and } \psi_{i}(\underline{\theta} ;[h, \bar{\theta}]) \geq 0 \text {. }
$$

Figure 1 illustrates these equilibrium conditions. The following proposition gives

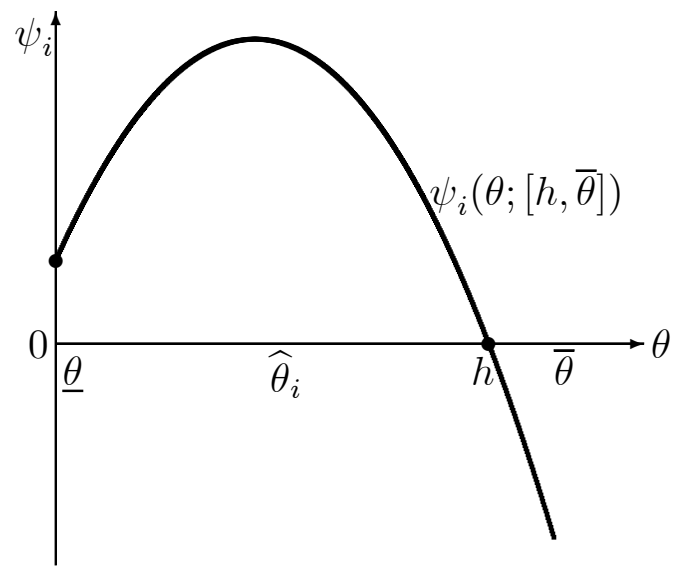

Figure 1: Sharing efficient technologies in equilibrium

necessary conditions for the existence of such an equilibrium.

Proposition 6 (a) If there exists an equilibrium with $\mathcal{S}_{i}=\left(h^{*}, \bar{\theta}\right]$ and $\mathcal{S}_{j}=\Theta$ for some $\widehat{\theta}_{i}<h^{*}<\bar{\theta}$, then condition $\left(C_{O}\right)$ holds. (b) If firms have identical technology distributions, then there exists no equilibrium with $\mathcal{S}_{i}=\left(h^{*}, \bar{\theta}\right]$ for any $\widehat{\theta}_{i}<h^{*}<\bar{\theta}$.

Part (a) states that condition $\left(\mathrm{C}_{O}\right)$ is a necessary condition for the existence of such an equilibrium. Under this condition the expropriation effect is weak enough, and it makes the sharing of efficient technologies profitable. That is, whenever there 
is an equilibrium in which firm $i$ shares only its best technology draws, there also exists an equilibrium in which firm $i$ shares all technologies. Part (b) shows that an equilibrium in which one of the firms shares the best technologies can only emerge under special circumstances. It cannot emerge in a symmetric model. By contrast, full concealment and full technology sharing can emerge in equilibrium under symmetry.

Finally, Proposition 7 gives specific, sufficient conditions for the existence of an equilibrium with sharing of only the best technologies by firm $i$.

Proposition 7 Suppose that condition $\left(C_{O}\right)$ holds with strict inequality. Consider the critical value $\widetilde{\theta}$, with $\widehat{\theta}_{i}<\widetilde{\theta}<\bar{\theta}$, such that $\psi_{i}\left(\widetilde{\theta} ; \mathcal{S}_{i}\right)=\psi_{i}\left(\underline{\theta} ; \mathcal{S}_{i}\right)$, and a distribution $\widetilde{F}_{i}$ such that $\left.\psi_{i}(\widetilde{\theta} ; \tilde{\theta}, \bar{\theta}]\right)=0$. Then for any distribution $G_{i}$ with $E_{G_{i}}\left\{\theta_{i} \mid \theta_{i}>\widetilde{\theta}\right\} \leq$ $E_{\widetilde{F}_{i}}\left\{\theta_{i} \mid \theta_{i}>\widetilde{\theta}\right\}$, there is a critical value $h^{*}$, with $\widetilde{\theta} \leq h^{*}<\bar{\theta}$, such that there exists an equilibrium with $\mathcal{S}_{i}=\left(h^{*}, \bar{\theta}\right]$ and $\mathcal{S}_{j}=\Theta$.

As before, condition $\left(\mathrm{C}_{O}\right)$ ensures that the expropriation effect is sufficiently weak. The restriction on the technology distribution $G_{i}$ simplifies as follows for an exponentially distributed technology. Suppose that firm $i$ draws its technology from $\Theta=$ $[0,1]$ by the truncated exponential distribution $F\left(\theta ; \lambda_{i}\right) \equiv\left(1-e^{-\lambda_{i} \theta}\right) /\left(1-e^{-\lambda_{i}}\right)$ for $\lambda_{i}>0$. The inverse hazard rate parameter, $\lambda_{i}$, measures the skewness of firm $i$ 's distribution towards efficient technologies. Then the critical parameter value $\widetilde{\lambda}_{i}$ exists, with $0<\widetilde{\lambda}_{i}<\infty$, such that $\left.\psi_{i}(\widetilde{\theta} ; \tilde{\theta}, \bar{\theta}]\right)=0$ for $\lambda_{i}=\widetilde{\lambda}_{i}$. If $\lambda_{i}>\widetilde{\lambda}_{i}$, then the condition $E_{\lambda_{i}}\left\{\theta_{i} \mid \theta_{i}>h\right\} \leq E_{\widetilde{\lambda}_{i}}\left\{\theta_{i} \mid \theta_{i}>h\right\}$ is satisfied for all $h .^{14}$ In other words, for exponential distributions that are sufficiently skewed towards efficient technologies, the equilibrium condition on firm $i$ 's distribution is satisfied.

\subsubsection{Share Only Intermediate Technologies}

In this subsection I characterize conditions under which a firm shares technologies of intermediate efficiency, while it conceals very inefficient and very efficient technologies. That is, I analyze the sharing strategy $s_{i}$ with $\mathcal{O}_{i}=[l, h]$ and $\mathcal{S}_{i}=\Theta \backslash[l, h]$ for firm $i$, where $\underline{\theta}<l<\widehat{\theta}_{i}<h<\bar{\theta}$. By Proposition 2, firm $j$ conceals all technologies.

The equilibrium conditions for firm $i$ to share only technologies with $\theta_{i} \in[l, h]$, while firm $j$ conceals all information, are as follows:

$$
\left.\psi_{i}(y ; \Theta \backslash[l, h]\}\right)=0 \text {, for } y \in\{l, h\},
$$

\footnotetext{
${ }^{14}$ This follows from the fact that $E\left\{\theta_{i} \mid \theta_{i}>h\right\}$ is decreasing in $\lambda_{i}$ for any $h$, as can be easily shown.
} 
where the posterior expected cost of the selectively sharing firm equals:

$$
E\left\{\theta_{i} \mid \theta_{i} \notin[l, h]\right\}=\frac{F_{i}(l)}{F_{i}(l)+1-F_{i}(h)} E\left\{\theta_{i} \mid \theta_{i} \leq l\right\}+\frac{1-F_{i}(h)}{F_{i}(l)+1-F_{i}(h)} E\left\{\theta_{i} \mid \theta_{i}>h\right\} .
$$

Solving this system of equations yields equilibrium values for $l$ and $h$. The equilibrium conditions are illustrated in Figure 2. Below I characterize the conditions for the

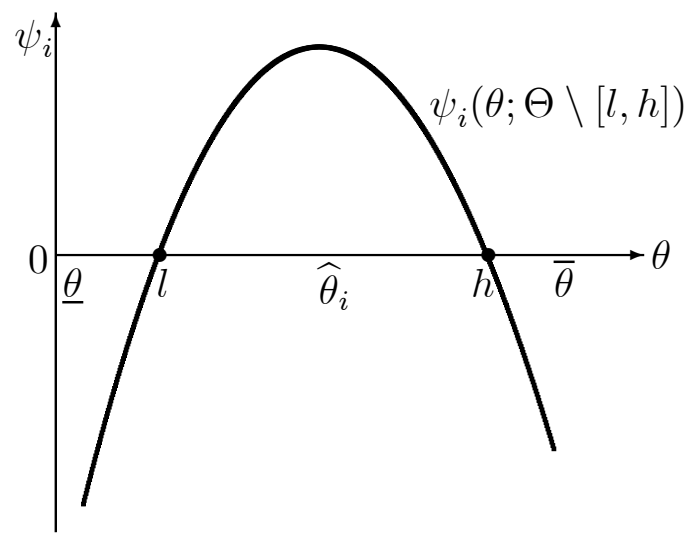

Figure 2: Sharing intermediate technologies in equilibrium

existence of a selective sharing equilibrium in two special cases.

To keep the analysis tractable, I first consider a symmetric model. For firms with identical technology distributions, the following proposition holds.

Proposition 8 Suppose that firms have identical technology distributions, and condition $\left(C_{O}\right)$ holds with strict inequality. Then there are critical values $l^{*}$ and $h^{*}$, with $\underline{\theta}<l^{*}<\widehat{\theta}_{i}<h^{*}<\bar{\theta}$, such that for some $i \in\{1,2\}$ there exists an equilibrium with $\mathcal{S}_{i}=\Theta \backslash\left[l^{*}, h^{*}\right]$ and $\mathcal{S}_{j}=\Theta$.

In other words, one of the firms has an incentive to share only intermediate technologies if the firms' technology distribution is skewed towards efficient technologies. In that case, the expropriation effect is relatively mild, and the signaling effect dominates for intermediate technologies.

Under the conditions of Proposition 8 there also exist equilibria with full concealment (Proposition 4), and full sharing by one of the firms (Proposition 5). However, Proposition 6(b) shows that in a symmetric model there exists no equilibrium in which one of the firms shares only its best technologies.

Second, I consider the situation where firms supply homogeneous goods $(\beta=1)$, and $\theta_{j}$ has a symmetric distribution on the interval $\Theta$, i.e. $E\left(\theta_{j}\right)=\widehat{\theta}_{i}=\frac{1}{2}(\underline{\theta}+\bar{\theta})$, and $f_{j}\left(\widehat{\theta}_{i}-\varepsilon\right)=f_{j}\left(\widehat{\theta}_{i}+\varepsilon\right)$ for any $\varepsilon \in\left[0, \frac{1}{2}(\bar{\theta}-\underline{\theta})\right]$. In this case the curve of $\psi_{i}$ 
is symmetric around $\theta_{i}=\widehat{\theta}_{i}$. Consequently, if an equilibrium exists in which firm $i$ shares selectively, then the interval of shared technologies is symmetric around $\widehat{\theta}_{i}$, i.e., $\mathcal{O}_{i}=\left[\widehat{\theta}_{i}-\varepsilon, \widehat{\theta}_{i}+\varepsilon\right]$ for some $\varepsilon \in\left[0, \frac{1}{2}(\bar{\theta}-\underline{\theta})\right]$. This observation simplifies the analysis of the technology-sharing incentives considerably.

Proposition 9 Suppose goods are homogeneous $(\beta=1)$, the distribution of $\theta_{j}$ is symmetric on $\Theta$, and condition $\left(C_{S}\right)$ is violated. Then there is an $\varepsilon^{*}$, with $0<\varepsilon^{*}<$ $\frac{1}{2}(\bar{\theta}-\underline{\theta})$, such that an there exists an equilibrium with $\mathcal{S}_{i}=\Theta \backslash\left[\widehat{\theta}_{i}-\varepsilon^{*}, \widehat{\theta}_{i}+\varepsilon^{*}\right]$ and $\mathcal{S}_{j}=\Theta$ for $i, j=1,2$ and $i \neq j$.

In other words, if firm $i$ 's cost distribution is sufficiently skewed towards inefficient technologies, while its rival's distribution is non-skewed, then the firm has an incentive to share only intermediately efficient technologies in equilibrium. The intuition for the technology sharing incentives of intermediate types is similar to the intuition for the incentive to deviate from full secrecy (see subsection 4.2.1). Extreme types, e.g., $\theta_{i} \in\{\underline{\theta}, \bar{\theta}\}$, have an incentive to keep their technologies secret. First, firm $i$ with the least efficient technology $(\bar{\theta})$ has an incentive for secrecy, since technology sharing would yield a strategic loss (while expropriation is irrelevant). Second, the firm with the most efficient technology $(\underline{\theta})$ also has no incentive to share. As shown in Proposition 5, the signaling effect exactly offsets the expropriation effect for firm $i$ if firm $j$ would believe that a secretive firm $i$ has the least efficient technology, $\bar{\theta}$. Such an extreme belief is, however, inconsistent with selective technology sharing. Since the p.d.f. $f_{i}$ has full support on type space $\Theta$, consistent beliefs would give a lower expected cost, i.e., $E\left\{\theta_{i} \mid \theta_{i} \notin\left[\widehat{\theta}_{i}-\varepsilon^{*}, \widehat{\theta}_{i}+\varepsilon^{*}\right]\right\}<\bar{\theta}$. Consequently, the equilibrium beliefs are such that the expropriation effect outweighs the signaling effect for firm $i$ with the most efficient technology.

Notice that under the assumptions of Proposition 9 there does not exist an equilibrium with full concealment, since the condition $\left(\mathrm{C}_{S}\right)$ is violated (see Proposition $4)$. On the other hand, for a symmetric distribution of $\theta_{j}$ and homogeneous goods $(\beta=1)$ the condition $\left(\mathrm{C}_{O}\right)$ is satisfied and binding. Therefore, there also exists an equilibrium with full sharing by firm $i$ (see Proposition 5).

Finally, the results in this subsection are notably different from the existing results. For example, Jansen (2010a) shows that in a model with one-sided asymmetric information, and an exogenous probability of imitation, there is no equilibrium in which the informed firm shares only intermediate technologies. This gives a contribution beyond endogenizing the identity of the firm that shares its technology. The introduction of two-sided asymmetric information generates a new equilibrium strategy. 


\subsection{An Example}

In this subsection I illustrate the technology sharing strategies for exponentially distributed cost parameters. I assume that the technology space is simply $\Theta=[0,1]$, and goods are homogeneous (i.e., $\beta=1$ ). The truncated exponential distribution function is $F\left(\theta ; \lambda_{i}\right) \equiv\left(1-e^{-\lambda_{i} \theta}\right) /\left(1-e^{-\lambda_{i}}\right)$, and the corresponding density function is $f\left(\theta ; \lambda_{i}\right) \equiv \lambda_{i} e^{-\lambda_{i} \theta} /\left(1-e^{-\lambda_{i}}\right)$ for $\lambda_{i}>0, \theta \in[0,1]$, and $i=1,2$. The parameter $\lambda_{i}$ is a measure of the skewness of the distribution. For $\lambda_{i} \rightarrow 0$ this distribution converges to the uniform distribution, while an increase of $\lambda_{i}$ skews the distribution towards efficient technologies.

Figure 3 illustrates the equilibrium conditions of Propositions 4-7 for truncated exponential distributions. For the entire parameter space $(0, \infty)^{2}$ there always exists

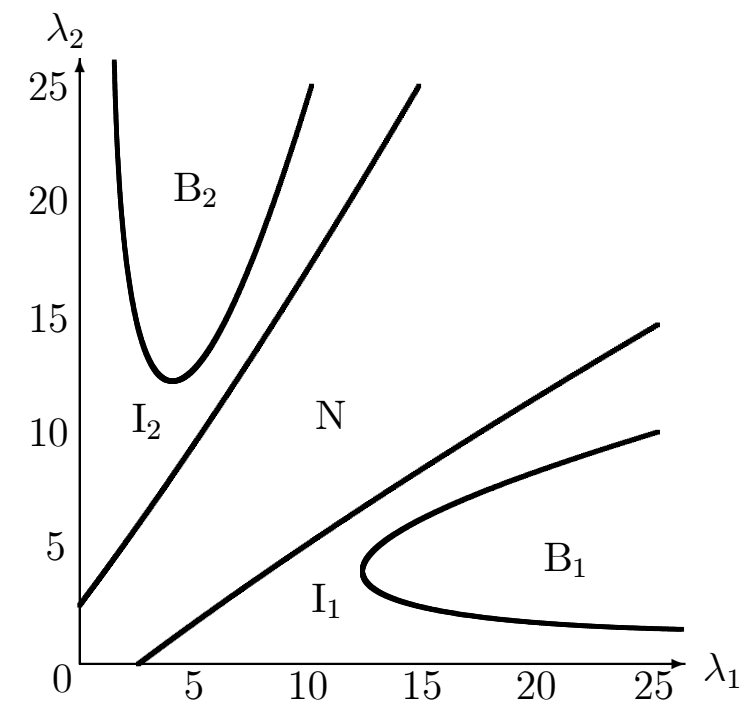

Figure 3: Strategic technology sharing (truncated exponential distributions)

an equilibrium in which one of the firms shares all technologies. This follows from the fact that the strength of the expropriation effect is moderate, since the exponential distribution is skewed towards efficient technologies. The area $\mathrm{N}$ contains those parameter values for which both firms conceal all technologies in equilibrium. In this area the parameters $\lambda_{i}$ and $\lambda_{j}$ are of similar size. In area $\mathrm{B}_{i}$ there exists an equilibrium in which firm $i$ shares only its best technologies, for $i=1,2$. Here the technology distribution of firm $i$ has relatively greater skewness towards efficient technologies. These parameter combinations correspond to asymmetric models, as Proposition 6 (b) shows. Finally, numerical examples suggest that for parameter values in the areas $\mathrm{I}_{i}$ and $\mathrm{N}$ there exist equilibria in which firm $i$ shares only intermediate technologies, 
for $i=1,2$. Proposition 8 shows that such an equilibrium exists along the $45^{\circ}$ line (i.e., for $\lambda_{i}=\lambda_{j}$ in area N). In addition, Proposition 9 shows that this equilibrium exists along the axis with $\lambda_{j}=0$ (i.e., in area $\mathrm{I}_{i}$ ) for $j \neq i$. The example illustrates that there are many other situations where the strategy may emerge in equilibrium.

\section{Precommitment to Share Technologies}

So far, I assumed that a firm makes strategic technology-sharing decisions. This assumption is appropriate when the technology-sharing decision is a short-term decision (e.g., adopting a Berkeley open source license). However, there are cases in which long-term technology-sharing decision is more realistic (e.g., in case of adopting a GPL open source license). Therefore, I consider here the game in which the firms choose between technology sharing and secrecy before they learn the realization of their technologies. ${ }^{15}$

The proof of Proposition 2 has the following immediate implication.

Corollary 1 There exists no equilibrium in which both firms commit to share their technologies.

Proof. If firm $j$ commits to share its technology, then (A.2) in the Appendix implies that firm $i$ prefers to commit to secrecy for any $i, j=1,2$ with $i \neq j$.

Given concealment by the competitor, firm $i$ expects the profit $E\left\{\Pi_{i}^{o}\left(\theta_{i} ; \Theta\right)\right\}$ from committing to technology sharing, and $E\left\{\Pi_{i}^{s}\left(\theta_{i} ; \Theta, \Theta\right)\right\}$ from committing to concealment, where $\Pi_{i}^{o}$ and $\Pi_{i}^{s}$ are defined in (4.1) and (4.2), respectively. Hence, firm $i$ 's choice between committing to share or conceal its technologies depends on the sign of $E\left\{\Psi\left(\theta_{i} ; \Theta, \Theta\right)\right\}$, with $\Psi$ as in (4.3). This gives the following immediate result.

Corollary 2 If condition $\left(C_{S}\right)$ holds for all $i, j=1,2$ with $i \neq j$, then both firms commit to secrecy in the unique equilibrium.

Proof. Condition $\left(\mathrm{C}_{S}\right)$ implies that $\Psi\left(\theta_{i} ; \Theta, \Theta\right) \leq 0$ for all $\theta_{i} \in \Theta$, which gives $E\left\{\Psi\left(\theta_{i} ; \Theta, \Theta\right)\right\}<0$.

In other words, condition $\left(\mathrm{C}_{S}\right)$ is a sufficient condition for the emergence of an equilibrium in which all technologies are kept secret. However, unlike the result in

\footnotetext{
${ }^{15}$ For example, Gal-Or (1986), and Shapiro (1986) also study models where firms precommit to disclose their technologies. These models can be interpreted as models with perfect protection of intellectual property (i.e., no imitation upon disclosure), whereas I study a model with no protection.
} 
Proposition 4, the condition is not necessary for complete secrecy in equilibrium. A precommitting firm should be on average better off under technology concealment, whereas a strategic firm should prefer concealment for every possible technology realization. Clearly, the former requirement is weaker than the latter, which gives a greater incentives to precommit to technology concealment.

Figure 4 illustrates the result of Corollary 2 for truncated exponential distributions (i.e., $F\left(\theta ; \lambda_{i}\right) \equiv\left(1-e^{-\lambda_{i} \theta}\right) /\left(1-e^{-\lambda_{i}}\right)$ with $\lambda_{i}>0$ and $\theta \in[0,1]$ for $\left.i=1,2\right)$, a demand intercept of $\alpha=4$, and homogeneous goods $(\beta=1)$. For parameter values in

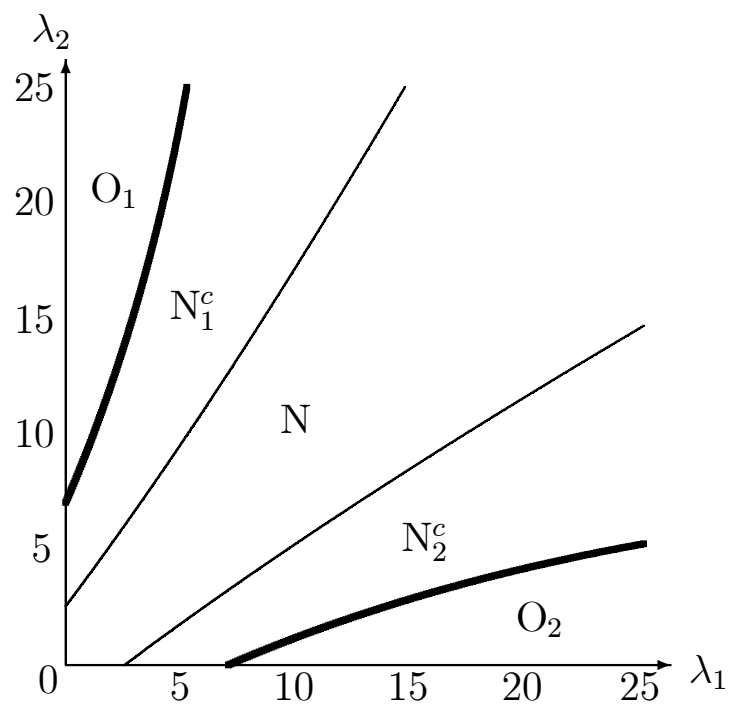

Figure 4: Commitment to share technologies (truncated exponential distributions)

area $\mathrm{O}_{i}$, firm $i$ precommits to share its technologies while firm $j$ precommits to conceal in equilibrium for $i, j \in\{1,2\}$ and $i \neq j$. For intermediate parameter values between the two bold lines (i.e., areas $\mathrm{N}_{1}^{c}-\mathrm{N}-\mathrm{N}_{2}^{c}$ ), both firms commit to keep their technologies secret in equilibrium. As in Figure 3, only for parameter values between the thin lines $($ area $\mathrm{N})$, there exists an equilibrium in which strategic firms conceal all technologies. Clearly, for the parameter values between the bold and thin lines (areas $\mathrm{N}_{1}^{c}$ and $\mathrm{N}_{2}^{c}$ ), precommitting firms conceal in equilibrium, but there exists no equilibrium in which two strategic firms conceal all technologies.

In Figure 4, a precommitting firm does not share its technology in all the cases where a strategic firm would share. In the game with commitment, an equilibrium with technology sharing only exists for parameter values in the areas $\mathrm{O}_{i}$ and $\mathrm{O}_{j}$. By contrast, with strategic sharing, an equilibrium with technology sharing exists for all positive $\left(\lambda_{i}, \lambda_{j}\right)$. However, it is unclear whether this holds in general. On the one hand, precommitting firms could have weaker technology-sharing incentives, 
since unraveling does not occur with non-strategic choices (i.e., skeptical beliefs are inconsistent with precommitment strategies). On the other hand, precommitting firms could have stronger incentives to share all technologies, since they only need to be made better off on average, and not for all technology realizations.

\section{Conclusion}

In this paper I characterized the conditions under which firms share their technologies in the absence of intellectual property rights. The paper finds conditions on the technology distributions for the emergence of competition between an open and a proprietary technology standard. Coexistence between open and proprietary technologies may emerge endogenously in equilibrium of a symmetric model. Further, there may exist equilibria in which one of the firms shares selectively by sharing only intermediate technologies. These results cannot be obtained in models with one-sided asymmetric information. Herein lies the paper's contribution.

In particular, for firms with identical technology distributions, there exist at most three kinds of equilibrium strategies. First, there always exists an equilibrium in which both firms conceal their technologies. Second, if the distributions are sufficiently skewed towards efficient technologies, there also exist equilibria in which one firm shares all technologies. Finally, for such skewed distributions there exist also equilibria in which one firm shares intermediate technologies while all other technologies are kept secret. For firms with different technology distributions, an additional kind of strategy may be chosen in equilibrium. In such an equilibrium one firm shares only its best technologies while all other technologies are concealed. No other kinds of technology-sharing strategies can be chosen in equilibrium.

Firms in this paper choose their technology-sharing strategies simultaneously. In alternative settings, a firm may respond to its competitor's shared technology by choosing its technology-sharing strategy conditional on the shared technology. It could be interesting to compare the paper's equilibria with the equilibria that emerge in a model with sequential technology-sharing choices. The paper's analysis has an important implication for the equilibria of such a model. By applying the logic of Proposition 2, it is immediate that at most one firm shares its technology along any equilibrium path. The best response of a follower to any shared technology of a leader is to adopt secrecy. A more detailed characterization of equilibrium strategies awaits future research. 
The analysis above assumes that there is no protection of intellectual property and imitation is costless. This is an extreme assumption which can be relaxed. The same qualitative results emerge in a model with sufficiently weak protection of intellectual property rights. However, for sufficiently strong intellectual property rights, the results are unlikely to hold. In particular, if intellectual property rights give perfect protection against imitation, then firms have an incentive to patent all technologies (Okuno-Fujiwara et al., 1990), since the expropriation effect disappears. It would be interesting to analyze what strategies can be chosen in equilibrium between the extremes of perfect and no protection.

The paper considers perfectly substitutable technologies, as many other related papers do (e.g., Anton and Yao, 2003-4, Gill, 2008, Jansen, 2006, 2011). The introduction of slight imperfections in substitutability would not affect the qualitative results. However, in the absence of substitutability, the results are different. In the extreme, where technologies are perfect complements, firms can produce at the worst available efficiency level (not the best). That is, a firm with technology $\theta_{i}$ obtains technology $\max \left\{\theta_{i}, \theta_{j}\right\}$ if its competitor shares technology $\theta_{j}$, and it obtains $\bar{\theta}$ if the competitor conceals its technology. Firms with perfectly complementary technologies conceal all technologies in the unique equilibrium. First, if a firm's competitor shares its technology, then the firm faces a trade-off between expropriation and signaling. As in the model with perfectly substitutable technologies, the expropriation effect dominates in this situation. Second, if the competitor keeps its technology secret, then technology sharing has no signaling effect. Unilateral technology sharing enables the competitor to improve its technology (from $\bar{\theta}$ to $\max \left\{\theta_{i}, \theta_{j}\right\}$ ), while the sharing firm remains with technology $\bar{\theta}$. By contrast, with perfectly substitutable technologies there is a trade-off between the two opposing effects in this case. It could be interesting to study the technology-sharing strategies between the extremes of perfect substitutability and perfect complementarity.

This analysis may have implications for the incentives of firms to invest in research and development (R\&D). The technology distribution has been assumed to be exogenous. In practice, however, a firm may affect the technology distribution by investing in R\&D. Suppose that a firm can change the skewness of the technology distribution through an investment in $\mathrm{R} \& \mathrm{D}$. The more the firm invests, the more the distribution becomes skewed towards the efficient technology. In this case, a unilateral increase of the firm's investment does not only have the direct effect of increasing the firm's expected efficiency. It also may change the technology-sharing incentives of the firm's 
rival in the product market. In particular, an investment increase may give a greater incentive to the rival to share its technology. This indirect effect may interact in an interesting way with the direct effect of R\&D investments. Further analysis of this interaction awaits future research. ${ }^{16}$

\section{A Appendix}

This Appendix provides proofs to the propositions.

\section{Proof of Proposition 1}

Suppose there does exist an equilibrium with $\mathcal{S}_{i}=[\underline{\theta}, l]$ for some $\underline{\theta}<l<\bar{\theta}$. Then firm $i$ prefers to hide technologies close to $\bar{\theta}$, since evaluating $\Psi$ in (4.3) at $\theta_{i}=\bar{\theta}$ gives:

$$
\begin{aligned}
\Psi\left(\bar{\theta} ;[\underline{\theta}, l], \mathcal{S}_{j}\right) \equiv & \int_{\theta_{j} \in \mathcal{O}_{j}}\left[x_{i}^{o o}\left(\bar{\theta}, \theta_{j}\right)^{2}-x_{i}^{s o}\left(\bar{\theta}, \theta_{j} ;[\underline{\theta}, l]\right)^{2}\right] d F_{j}\left(\theta_{j}\right) \\
& +\operatorname{Pr}\left[\theta_{j} \in \mathcal{S}_{j}\right]\left[x_{i}^{o s}\left(\bar{\theta} ; \mathcal{S}_{j}\right)^{2}-x_{i}^{s s}\left(\bar{\theta} ;[\underline{\theta}, l], \mathcal{S}_{j}\right)^{2}\right]<0
\end{aligned}
$$

since:

$$
x_{i}^{o o}\left(\bar{\theta}, \theta_{j}\right)-x_{i}^{s o}\left(\bar{\theta}, \theta_{j} ;[\underline{\theta}, l]\right)=-\frac{\beta^{2}}{2}\left[\theta_{j}-E\left(\min \left\{\theta_{i}, \theta_{j}\right\} \mid \theta_{i} \leq l, \theta_{j}\right)\right] \leq 0
$$

with a strict inequality for any $\theta_{j}>\underline{\theta}$ and $\underline{\theta}<l<\bar{\theta}$, and

$$
x_{i}^{o s}\left(\bar{\theta} ; \mathcal{S}_{j}\right)-x_{i}^{s s}\left(\bar{\theta} ;[\underline{\theta}, l], \mathcal{S}_{j}\right)=\frac{-\beta^{2}\left[\bar{\theta}-E\left\{\theta_{i} \mid \theta_{i} \leq l\right\}\right]}{2\left(4-\beta^{2}\right)}<0
$$

for any $\underline{\theta}<l<\bar{\theta}$, and $\mathcal{S}_{j} \subseteq \Theta$. This gives a contradiction.

\section{Proof of Proposition 2}

The proof takes three steps. First, I show that the technology sharing incentives are particularly strong for intermediate values of the cost parameters. Consequently, in equilibrium the shared technologies of a firm have to form a single interval.

Lemma 1 In any equilibrium there are some bounds $l_{i}, h_{i} \in \Theta$, with $l_{i} \leq h_{i}$, such that firm $i$ chooses technology-sharing strategy $s_{i}$ with $\mathcal{O}_{i}=\left[l_{i}, h_{i}\right]$, for $i=1,2$.

\footnotetext{
${ }^{16}$ For this and other extensions, it may be useful to consider the model with a discrete technology space (i.e., $\Theta=\left\{\theta^{1}, \theta^{2}, \theta^{3}\right\}$ ) and densities (i.e., $p_{i}^{1}, p_{i}^{2}, p_{i}^{3}$ for firm $i$ ). A supplementary appendix characterizes the necessary and sufficient equilibrium conditions in such a discrete model. There I discuss the conditions in detail for symmetric models (i.e., $p_{1}^{m}=p_{2}^{m}$ for all $m$ ), and for models in which one firm has uniformly distributed technologies (i.e., $p_{j}^{m}=\frac{1}{3}$ for all $m$ ).
} 
Proof. The first derivative of $\Psi$ in (4.3) with respect to $\theta_{i}$ equals:

$$
\begin{aligned}
\frac{\partial \Psi\left(\theta_{i} ; \mathcal{S}_{i}, \mathcal{S}_{j}\right)}{\partial \theta_{i}} & =-\int_{\theta_{j} \in \mathcal{O}_{j} \cap\left[\theta_{i}, \bar{\theta}\right]}\left(\frac{2}{2+\beta} x_{i}^{o o}\left(\theta_{i}, \theta_{j}\right)-x_{i}^{s o}\left(\theta_{i}, \theta_{j} ; \mathcal{S}_{i}\right)\right) d F_{j}\left(\theta_{j}\right) \\
-\operatorname{Pr}\left[\theta_{j}\right. & \left.\in \mathcal{S}_{j}\right]\left(\frac{2\left(2-\beta\left[1-F_{j}\left(\theta_{i} \mid \theta_{j} \in \mathcal{S}_{j}\right)\right]\right)}{4-\beta^{2}} x_{i}^{o s}\left(\theta_{i} ; \mathcal{S}_{j}\right)-x_{i}^{s s}\left(\theta_{i} ; \mathcal{S}_{i}, \mathcal{S}_{j}\right)\right)
\end{aligned}
$$

since

$$
\begin{aligned}
& \frac{\partial}{\partial \theta_{i}}\left(\int_{\theta_{j} \in \mathcal{O}_{j}} x_{i}^{o o}\left(\theta_{i}, \theta_{j}\right)^{2} d F_{j}\left(\theta_{j}\right)\right)=\frac{\partial}{\partial \theta_{i}} \int_{\theta_{j} \in \mathcal{O}_{j} \cap\left[\underline{\theta}, \theta_{i}\right]} x_{i}^{o o}\left(\theta_{i}, \theta_{j}\right)^{2} d F_{j}\left(\theta_{j}\right) \\
& +\frac{\partial}{\partial \theta_{i}} \int_{\theta_{j} \in \mathcal{O}_{j} \cap\left[\theta_{i}, \bar{\theta}\right]} x_{i}^{o o}\left(\theta_{i}, \theta_{j}\right)^{2} d F_{j}\left(\theta_{j}\right) \\
& =\frac{-2}{2+\beta} \int_{\theta_{j} \in \mathcal{O}_{j} \cap\left[\theta_{i}, \bar{\theta}\right]} x_{i}^{o o}\left(\theta_{i}, \theta_{j}\right) d F_{j}\left(\theta_{j}\right) \\
& \frac{\partial}{\partial \theta_{i}}\left(\int_{\theta_{j} \in \mathcal{O}_{j}} x_{i}^{s o}\left(\theta_{i}, \theta_{j} ; \mathcal{S}_{i}\right)^{2} d F_{j}\left(\theta_{j}\right)\right)=\frac{\partial}{\partial \theta_{i}} \int_{\theta_{j} \in \mathcal{O}_{j} \cap\left[\underline{\theta}, \theta_{i}\right]} x_{i}^{s o}\left(\theta_{i}, \theta_{j} ; \mathcal{S}_{i}\right)^{2} d F_{j}\left(\theta_{j}\right) \\
& +\frac{\partial}{\partial \theta_{i}} \int_{\theta_{j} \in \mathcal{O}_{j} \cap\left[\theta_{i}, \bar{\theta}\right]} x_{i}^{s o}\left(\theta_{i}, \theta_{j} ; \mathcal{S}_{i}\right)^{2} d F_{j}\left(\theta_{j}\right) \\
& =-\int_{\theta_{j} \in \mathcal{O}_{j} \cap\left[\theta_{i}, \bar{\theta}\right]} x_{i}^{s o}\left(\theta_{i}, \theta_{j} ; \mathcal{S}_{i}\right) d F_{j}\left(\theta_{j}\right) \\
& \frac{\partial}{\partial \theta_{i}} x_{i}^{o s}\left(\theta_{i} ; \mathcal{S}_{j}\right)^{2}=\frac{-2}{4-\beta^{2}}\left(2-\beta\left[1-F_{j}\left(\theta_{i} \mid \theta_{j} \in \mathcal{S}_{j}\right)\right]\right) x_{i}^{o s}\left(\theta_{i} ; \mathcal{S}_{j}\right) \\
& \frac{\partial}{\partial \theta_{i}} x_{i}^{s s}\left(\theta_{i} ; \mathcal{S}_{i}, \mathcal{S}_{j}\right)^{2}=-x_{i}^{s s}\left(\theta_{i} ; \mathcal{S}_{i}, \mathcal{S}_{j}\right)
\end{aligned}
$$

The second derivative of $\Psi$ equals:

$$
\begin{aligned}
\frac{\partial^{2} \Psi\left(\theta_{i} ; \mathcal{S}_{i}, \mathcal{S}_{j}\right)}{\partial \theta_{i}^{2}}= & \operatorname{Pr}\left[\theta_{j} \in \mathcal{S}_{j}\right]\left(\frac{2}{(2+\beta)^{2}}-\frac{1}{2}\right)\left[1-F_{j}\left(\theta_{i} \mid \theta_{j} \in \mathcal{S}_{j}\right)\right] \\
+ & I^{o}\left(\theta_{i}\right)\left(\frac{2}{2+\beta} x_{i}^{o o}\left(\theta_{i}, \theta_{i}\right)-x_{i}^{s o}\left(\theta_{i}, \theta_{i} ; \mathcal{S}_{i}\right)\right) f_{j}\left(\theta_{i}\right) \\
+ & \operatorname{Pr}\left[\theta_{j} \in \mathcal{S}_{j}\right]\left[\frac{1}{\left(4-\beta^{2}\right)^{2}}\left(2-\beta\left[1-F_{j}\left(\theta_{i} \mid \theta_{j} \in \mathcal{S}_{j}\right)\right]\right)^{2}-\frac{1}{2}\right] \\
& -\left[1-I^{o}\left(\theta_{i}\right)\right] 2 x_{i}^{o s}\left(\theta_{i} ; \mathcal{S}_{j}\right) \frac{\beta}{4-\beta^{2}} f_{j}\left(\theta_{i}\right)
\end{aligned}
$$

where $I^{o}$ is the indicator function

$$
I^{o}\left(\theta_{i}\right)= \begin{cases}1, & \text { if } \theta_{i} \in \mathcal{O}_{j} \\ 0, & \text { if } \theta_{i} \notin \mathcal{O}_{j}\end{cases}
$$


Clearly, the function $\Psi$ is concave in $\theta_{i}$ since $\partial^{2} \Psi\left(\theta_{i} ; \mathcal{S}_{i}, \mathcal{S}_{j}\right) / \partial \theta_{i}^{2} \leq 0$ for any $\theta_{i}, \mathcal{S}_{i}, \mathcal{S}_{j}$. This implies that in equilibrium the technology sharing strategy is $s_{i}$ with $\mathcal{O}_{i}=\left[l_{i}, h_{i}\right]$ for some $l_{i}$ and $h_{i}$ with $\underline{\theta} \leq l \leq h \leq \bar{\theta}$.

Second, I find a necessary condition under which firm $i$ shares only the technologies $\theta_{i} \in[l, h]$ in equilibrium, with $\underline{\theta} \leq l<h \leq \bar{\theta}$. Lemma 1 shows that firm $i$ chooses no other strategy in equilibrium, if it shares some technologies.

Lemma 2 If firm $i$ has beliefs consistent with $s_{j}$ for some $\mathcal{S}_{j} \subseteq \Theta$, and it chooses $s_{i}$ with $\mathcal{O}_{i}=[l, h]$ in equilibrium, with $\underline{\theta} \leq l<h \leq \bar{\theta}$, then for all $\theta_{i}^{\prime} \in[l, h]$ :

$$
E_{j}\left(\min \left\{\theta_{i}^{\prime}, \theta_{j}\right\} \mid \theta_{j} \in \mathcal{S}_{j}\right)-E\left\{\theta_{j} \mid \theta_{j} \in \mathcal{S}_{j}\right\}+\frac{\beta}{2}\left[E\left\{\theta_{i} \mid \theta_{i} \notin[l, h]\right\}-\theta_{i}^{\prime}\right]>0 .
$$

Proof. The expected profit gain for firm $i$ of sharing technology $\theta_{i}, \Psi\left(\theta_{i} ; \mathcal{S}_{i}, \mathcal{S}_{j}\right)$ for any sets $\mathcal{S}_{i}, \mathcal{S}_{j} \subseteq \Theta$, is defined in (4.3). The first term of (4.3) is non-positive, since for any $\theta_{i}$ and $\theta_{j}$ :

$$
\begin{aligned}
x_{i}^{o o}\left(\theta_{i}, \theta_{j}\right)-x_{i}^{s o}\left(\theta_{i}, \theta_{j} ; \mathcal{S}_{i}\right)= & \frac{-\beta}{4-\beta^{2}}\left(\theta_{j}-\min \left\{\theta_{i}, \theta_{j}\right\}\right. \\
& \left.-\frac{\beta}{2}\left[E_{i}\left(\min \left\{\theta_{i}, \theta_{j}\right\} \mid \theta_{i} \in \mathcal{S}_{i}\right)-\min \left\{\theta_{i}, \theta_{j}\right\}\right]\right) \\
\leq & \frac{-\beta\left(1-\frac{1}{2} \beta\right)}{4-\beta^{2}}\left(\theta_{j}-\min \left\{\theta_{i}, \theta_{j}\right\}\right) \leq 0
\end{aligned}
$$

Therefore, any expected gain from sharing a technology is created by the second term of (4.3). A necessary condition for sharing technologies in $[l, h]$ by firm $i$, with beliefs consistent with secrecy of technologies in $\mathcal{S}_{j} \subseteq \Theta$, is that the second term of $\Psi\left(\theta_{i} ; \Theta \backslash[l, h], \mathcal{S}_{j}\right)$ in $(4.3)$ is positive for $\theta_{i}^{\prime} \in[l, h]$. This necessary condition reduces to $x_{i}^{o s}\left(\theta_{i}^{\prime} ; \mathcal{S}_{j}\right)>x_{i}^{s s}\left(\theta_{i}^{\prime} ; \Theta \backslash[l, h], \mathcal{S}_{j}\right)$, which is equivalent to (A.1).

Notice that (A.1) reduces to $\Upsilon_{i}\left(\theta_{i}^{\prime}\right)>0$ for $\theta_{i}^{\prime} \in[l, h]$ with: $\Upsilon_{i}\left(\theta_{i}^{\prime}\right) \equiv-\left[1-F_{j}\left(\theta_{i}^{\prime} \mid \theta_{j} \in \mathcal{S}_{j}\right)\right]\left(E\left\{\theta_{j} \mid \theta_{j}>\theta_{i}^{\prime}, \theta_{j} \in \mathcal{S}_{j}\right\}-\theta_{i}^{\prime}\right)+\frac{\beta}{2}\left[E\left\{\theta_{i} \mid \theta_{i} \notin[l, h]\right\}-\theta_{i}^{\prime}\right]$

Finally, I show that the necessary condition (A.1) implies that firm $j$ has no incentive to share any technology.

Lemma 3 If condition (A.1) holds for $\theta_{i}^{\prime} \in[l, h]$, and firm $j$ has beliefs consistent with $s_{i}$ for $\mathcal{O}_{i}=[l, h]$, then firm $j$ does not share any technology in equilibrium (i.e., $\left.\mathcal{S}_{j}=\Theta\right)$. 
Proof. The expected profit gain of firm $j$ from sharing the technology $\theta_{j}$ is $\Psi\left(\theta_{j} ; \mathcal{S}_{j}, \Theta \backslash[l, h]\right)$ as defined in (4.3). The firm can only have an incentive to share a technology $\theta_{j}$ if the second term of $\Psi\left(\theta_{j} ; \mathcal{S}_{j}, \Theta \backslash[l, h]\right)$ is positive. (The first term is negative due to (A.2) for firm $j$.) This second term is positive if $x_{j}^{o s}\left(\theta_{j} ; \Theta \backslash[l, h]\right)>$ $x_{j}^{s s}\left(\theta_{j} ; \mathcal{S}_{j}, \Theta \backslash[l, h]\right)$, which reduces to $\Upsilon_{j}\left(\theta_{j}\right)>0$, where:

$$
\Upsilon_{j}\left(\theta_{j}\right) \equiv \frac{\beta}{2}\left[E\left\{\theta_{j} \mid \theta_{j} \in \mathcal{S}_{j}\right\}-\theta_{j}\right]-E_{i}\left(\theta_{i}-\min \left\{\theta_{i}, \theta_{j}\right\} \mid \theta_{i} \notin[l, h]\right)
$$

with

$$
E_{i}\left(\theta_{i}-\min \left\{\theta_{i}, \theta_{j}\right\} \mid \theta_{i} \notin[l, h]\right)= \begin{cases}\int_{\theta_{j}}^{l} \frac{\left(\theta-\theta_{j}\right) f_{i}(\theta)}{F_{i}(l)+1-F_{i}(h)} d \theta+\int_{h}^{\bar{\theta}} \frac{\left(\theta-\theta_{j}\right) f_{i}(\theta)}{F_{i}(l)+1-F_{i}(h)} d \theta, & \text { if } \theta_{j}<l \\ \int_{\max \left\{\theta_{j}, h\right\}}^{\bar{\theta}} \frac{\left(\theta-\theta_{j}\right) f_{i}(\theta)}{F_{i}(l)+1-F_{i}(h)} d \theta, & \text { if } \theta_{j} \geq l\end{cases}
$$

The function $\Upsilon_{j}\left(\theta_{j}\right)$ is continuous in $\theta_{j}$. Moreover, it is concave in $\theta_{j}$, since:

$$
\frac{\partial}{\partial \theta_{j}} E_{i}\left(\theta_{i}-\min \left\{\theta_{i}, \theta_{j}\right\} \mid \theta_{i} \notin[l, h]\right)= \begin{cases}-\left(1-\frac{F_{i}\left(\theta_{j}\right)}{F_{i}(l)+1-F_{i}(h)}\right), & \text { if } \theta_{j}<l \\ -\left(\frac{1-F_{i}\left(\max \left\{\theta_{j}, h\right\}\right)}{F_{i}(l)+1-F_{i}(h)}\right), & \text { if } \theta_{j} \geq l\end{cases}
$$

and therefore $\frac{\partial^{2}}{\partial \theta_{j}^{2}} E_{i}\left(\theta_{i}-\min \left\{\theta_{i}, \theta_{j}\right\} \mid \theta_{i} \notin[l, h]\right) \geq 0$ for all $\theta_{j}$. The function reaches a global maximum for $\theta_{j}=\widetilde{\theta}$, with $\underline{\theta}<\widetilde{\theta}<\bar{\theta}$, since it is concave with $\Upsilon_{j}^{\prime}(\underline{\theta})=1-\frac{\beta}{2}>0$ and $\Upsilon_{j}^{\prime}(\bar{\theta})=-\frac{\beta}{2}<0$. I distinguish two cases.

(a) If $\frac{\beta}{2} F_{i}(l) \leq\left(1-\frac{\beta}{2}\right)\left[1-F_{i}(h)\right]$, then $\frac{1-F_{i}(\widetilde{\theta})}{F_{i}(l)+1-F_{i}(h)}=\frac{\beta}{2}$ and $\widetilde{\theta} \geq h$. In that case, for any $\theta_{i}^{\prime} \in[l, h]$ the following holds:

$$
\begin{aligned}
\Upsilon_{j}(\widetilde{\theta}) & =\frac{\beta}{2}\left[E\left\{\theta_{j} \mid \theta_{j} \in \mathcal{S}_{j}\right\}-\tilde{\theta}\right]-\int_{\widetilde{\theta}}^{\bar{\theta}} \frac{(\theta-\widetilde{\theta}) f_{i}(\theta)}{F_{i}(l)+1-F_{i}(h)} d \theta \\
& =\frac{\beta}{2}\left(\left[E\left\{\theta_{j} \mid \theta_{j} \in \mathcal{S}_{j}\right\}-\widetilde{\theta}\right]-\int_{\tilde{\theta}}^{\bar{\theta}} \frac{(\theta-\widetilde{\theta}) f_{i}(\theta)}{1-F_{i}(\widetilde{\theta})} d \theta\right) \\
& =\frac{\beta}{2}\left(E\left\{\theta_{j} \mid \theta_{j} \in \mathcal{S}_{j}\right\}-E\left\{\theta_{i} \mid \theta_{i}>\widetilde{\theta}\right\}\right) \\
& <\frac{\beta}{2}\left(E_{j}\left(\min \left\{\theta_{i}^{\prime}, \theta_{j}\right\} \mid \theta_{j} \in \mathcal{S}_{j}\right)+\frac{\beta}{2}\left[E\left\{\theta_{i} \mid \theta_{i} \notin[l, h]\right\}-\theta_{i}^{\prime}\right]-E\left\{\theta_{i} \mid \theta_{i}>\widetilde{\theta}\right\}\right) \\
& \leq \frac{\beta}{2}\left(\frac{\beta}{2} E\left\{\theta_{i} \mid \theta_{i} \notin[l, h]\right\}+\left(1-\frac{\beta}{2}\right) \theta_{i}^{\prime}-E\left\{\theta_{i} \mid \theta_{i}>\widetilde{\theta}\right\}\right)<0
\end{aligned}
$$

The first inequality follows from (A.1). The observation $E_{j}\left(\min \left\{\theta_{i}^{\prime}, \theta_{j}\right\} \mid \theta_{j} \in \mathcal{S}_{j}\right) \leq \theta_{i}^{\prime}$ gives the second inequality. The last inequality follows from $E\left\{\theta_{i} \mid \theta_{i} \notin[l, h]\right\}=$ 
$\frac{F_{i}(l)}{F_{i}(l)+1-F_{i}(h)} E\left\{\theta_{i} \mid \theta_{i} \leq l\right\}+\frac{1-F_{i}(h)}{F_{i}(l)+1-F_{i}(h)} E\left\{\theta_{i} \mid \theta_{i}>h\right\} \leq E\left\{\theta_{i} \mid \theta_{i}>h\right\} \leq E\left\{\theta_{i} \mid \theta_{i}>\widetilde{\theta}\right\}$ and $\theta_{i}^{\prime} \leq h \leq \widetilde{\theta}<E\left\{\theta_{i} \mid \theta_{i}>\widetilde{\theta}\right\}$.

(b) If $\frac{\beta}{2} F_{i}(l)>\left(1-\frac{\beta}{2}\right)\left[1-F_{i}(h)\right]$, then $\frac{F_{i}(\widetilde{\theta})}{F_{i}(l)+1-F_{i}(h)}=1-\frac{\beta}{2}$ and $\widetilde{\theta}<l$. Then for any $\theta_{i}^{\prime} \in[l, h]$ the following holds:

$$
\begin{aligned}
\Upsilon_{j}(\widetilde{\theta})= & \frac{\beta}{2}\left[E\left\{\theta_{j} \mid \theta_{j} \in \mathcal{S}_{j}\right\}-\widetilde{\theta}\right]-\int_{\widetilde{\theta}}^{l} \frac{(\theta-\widetilde{\theta}) f_{i}(\theta)}{F_{i}(l)+1-F_{i}(h)} d \theta-\int_{h}^{\bar{\theta}} \frac{(\theta-\widetilde{\theta}) f_{i}(\theta)}{F_{i}(l)+1-F_{i}(h)} d \theta \\
= & \frac{\beta}{2} E\left\{\theta_{j} \mid \theta_{j} \in \mathcal{S}_{j}\right\}-\int_{\widetilde{\theta}}^{l} \frac{\theta f_{i}(\theta)}{F_{i}(l)+1-F_{i}(h)} d \theta-\int_{h}^{\bar{\theta}} \frac{\theta f_{i}(\theta)}{F_{i}(l)+1-F_{i}(h)} d \theta \\
= & \frac{\beta}{2} E\left\{\theta_{j} \mid \theta_{j} \in \mathcal{S}_{j}\right\}+\left(1-\frac{\beta}{2}\right) E\left\{\theta_{i} \mid \theta_{i} \leq \widetilde{\theta}\right\}-E\left\{\theta_{i} \mid \theta_{i} \notin[l, h]\right\} \\
< & \frac{\beta}{2}\left(E_{j}\left(\min \left\{\theta_{i}^{\prime}, \theta_{j}\right\} \mid \theta_{j} \in \mathcal{S}_{j}\right)+\frac{\beta}{2}\left[E\left\{\theta_{i} \mid \theta_{i} \notin[l, h]\right\}-\theta_{i}^{\prime}\right]\right) \\
& +\left(1-\frac{\beta}{2}\right) E\left\{\theta_{i} \mid \theta_{i} \leq \widetilde{\theta}\right\}-E\left\{\theta_{i} \mid \theta_{i} \notin[l, h]\right\} \\
= & \frac{\beta}{2}\left[E_{j}\left(\min \left\{\theta_{i}^{\prime}, \theta_{j}\right\} \mid \theta_{j} \in \mathcal{S}_{j}\right)-\theta_{i}^{\prime}\right]+\left(1-\frac{\beta}{2}\right)\left[E\left\{\theta_{i} \mid \theta_{i} \leq \widetilde{\theta}\right\}-\theta_{i}^{\prime}\right] \\
& -\left[1-\left(\frac{\beta}{2}\right)^{2}\right]\left[E\left\{\theta_{i} \mid \theta_{i} \notin[l, h]\right\}-\theta_{i}^{\prime}\right] \\
= & \frac{\beta}{2} F_{j}\left(\theta_{i}^{\prime} \mid \theta_{j} \in \mathcal{S}_{j}\right)\left[E\left\{\theta_{j} \mid \theta_{j} \leq \theta_{i}^{\prime}, \theta_{j} \in \mathcal{S}_{j}\right\}-\theta_{i}^{\prime}\right]+\left(1-\frac{\beta}{2}\right)\left[E\left\{\theta_{i} \mid \theta_{i} \leq \widetilde{\theta}\right\}-\theta_{i}^{\prime}\right] \\
& -\left[1-\left(\frac{\beta}{2}\right)^{2}\right]\left[E\left\{\theta_{i} \mid \theta_{i} \notin[l, h]\right\}-\theta_{i}^{\prime}\right] \\
< & 0
\end{aligned}
$$

The first inequality follows from the necessary condition (A.1). The last inequality follows from the facts that $E\left\{\theta_{j} \mid \theta_{j} \leq \theta_{i}^{\prime}, \theta_{j} \in \mathcal{S}_{j}\right\} \leq \theta_{i}^{\prime}$, from $E\left\{\theta_{i} \mid \theta_{i} \leq \widetilde{\theta}\right\}<\widetilde{\theta}<l \leq$ $\theta_{i}^{\prime}$, and from the observation that $\Upsilon_{i}\left(\theta_{i}^{\prime}\right)>0$ in (A.3) implies $E\left\{\theta_{i} \mid \theta_{i} \notin[l, h]\right\} \geq \theta_{i}^{\prime}$, since $E\left\{\theta_{j} \mid \theta_{j}>\theta_{i}^{\prime}, \theta_{j} \in \mathcal{S}_{j}\right\} \geq \theta_{i}^{\prime}$ and $F_{j}\left(\theta_{i}^{\prime} \mid \theta_{j} \in \mathcal{S}_{j}\right) \leq 1$.

Cases (a) and (b) imply that there exists no technology that firm $j$ wants to share, since $\Upsilon_{j}\left(\theta_{j}\right) \leq \Upsilon_{j}(\widetilde{\theta})<0$ for all $\theta_{j}$, and any $[l, h]$ and $\mathcal{S}_{j}$. Hence, the only equilibrium strategy that exists for firm $j$ is to conceal all technologies.

\section{Proof of Proposition 3}

The proof is a special case of the proof of Lemma 1 (see Proposition 2). 


\section{Proof of Proposition 4}

The proof is omitted, since it follows immediately from the argument in the text.

\section{Proof of Proposition 5}

Suppose firm $j$ has skeptical beliefs, i.e., $E\left(\theta_{i} \mid \theta_{i} \in \mathcal{S}_{i}\right)=\bar{\theta}$ or $\mathcal{S}_{i}=\{\bar{\theta}\}$. Firm $i$ has no incentive to conceal information, given skeptical beliefs, if $\psi_{i}\left(\theta_{i} ;\{\bar{\theta}\}\right) \geq 0$ for all $\theta_{i}$, where $\psi_{i}$ is defined in (4.4). Concavity of $\psi_{i}$ in $\theta_{i}$ reduces the equilibrium condition to $\min \left\{\psi_{i}(\underline{\theta} ;\{\bar{\theta}\}), \psi_{i}(\bar{\theta} ;\{\bar{\theta}\})\right\} \geq 0$. This inequality is satisfied if and only if $\left(\mathrm{C}_{O}\right)$ holds, since $\psi_{i}(\underline{\theta} ;\{\bar{\theta}\})=-\left(E\left\{\theta_{j}\right\}-\underline{\theta}\right)+\frac{\beta}{2}[\bar{\theta}-\underline{\theta}]$ and $\psi_{i}(\bar{\theta} ;\{\bar{\theta}\})=0$. Finally, Proposition 2 shows that firm $j$ conceals all $\theta_{j}$ in equilibrium.

\section{Proof of Proposition 6}

(a) For any $h^{*}$, with $\widehat{\theta}_{i}<h^{*}<\bar{\theta}$, a necessary condition for the existence of an equilibrium with $\mathcal{S}_{i}=\left[h^{*}, \bar{\theta}\right]$ is that $\psi_{i}\left(\underline{\theta} ;\left[h^{*}, \bar{\theta}\right]\right) \geq 0>\psi_{i}\left(\bar{\theta} ;\left[h^{*}, \bar{\theta}\right]\right)$, where $\psi_{i}$ is defined in (4.4). If $\left(\mathrm{C}_{O}\right)$ is violated, then $\psi_{i}\left(\underline{\theta} ; \mathcal{S}_{i}\right)<\psi_{i}\left(\bar{\theta} ; \mathcal{S}_{i}\right)$ for any $\mathcal{S}_{i}$, and the equilibrium condition cannot be satisfied.

(b) Take any $h^{*}$ in the interior of $\Theta$, and suppose that firms have identical distributions (i.e., $F_{i}(\theta)=F(\theta)$ for all $i$ ). If there would exist an equilibrium with $\mathcal{S}_{i}=\left[h^{*}, \bar{\theta}\right]$, then (i) $\psi_{i}\left(h^{*} ;\left[h^{*}, \bar{\theta}\right]\right)=0$, and (ii) $\psi_{i}\left(\underline{\theta} ;\left[h^{*}, \bar{\theta}\right]\right) \geq 0$. Using symmetry, condition (i) gives:

$$
\begin{aligned}
\psi_{i}\left(h^{*} ;\left[h^{*}, \bar{\theta}\right]\right) & =\frac{\beta}{2}\left[E\left\{\theta_{i} \mid \theta_{i}>h^{*}\right\}-h^{*}\right]-\left[1-F_{j}\left(h^{*}\right)\right]\left(E\left\{\theta_{j} \mid \theta_{j}>h^{*}\right\}-h^{*}\right) \\
& =\left(\frac{\beta}{2}-\left[1-F\left(h^{*}\right)\right]\right)\left[E\left\{\theta \mid \theta>h^{*}\right\}-h^{*}\right]=0
\end{aligned}
$$

This equality can only hold for $h^{*}=\widehat{\theta}_{i}\left(\equiv F^{-1}\left(1-\frac{\beta}{2}\right)\right)$. However, $\left.\psi_{i}\left(\widehat{\theta}_{i} ; \widehat{\theta}_{i}, \bar{\theta}\right]\right)=0$ implies $\left.\psi_{i}\left(\theta ; \widehat{\theta}_{i}, \bar{\theta}\right]\right)<0$ for all $\theta \neq \widehat{\theta}_{i}$, since $\psi_{i}\left(\theta_{i} ; \cdot\right)$ reaches the global maximum at $\widehat{\theta}_{i}$, which means that condition (ii) cannot be satisfied.

\section{Proof of Proposition 7}

For some $h^{*}$, with $\widehat{\theta}_{i}<h^{*}<\bar{\theta}$, there exists an equilibrium with $\mathcal{S}_{i}=\left[h^{*}, \bar{\theta}\right]$ and $\mathcal{S}_{j}=$ $\Theta$, if (4.7) holds for $h=h^{*}$. The conditions in (4.7) can be written as $\widetilde{\psi}\left(h^{*} ; F_{i}\right)=0$ and $\underline{\psi}\left(h^{*} ; F_{i}\right) \geq 0$ for the following continuous functions:

$$
\widetilde{\psi}\left(x ; F_{i}\right) \equiv \psi_{i}(x ;[x, \bar{\theta}])=\frac{\beta}{2}\left[E\left\{\theta_{i} \mid \theta_{i}>x\right\}-x\right]-\left[1-F_{j}(x)\right]\left(E\left\{\theta_{j} \mid \theta_{j}>x\right\}-x\right)
$$




$$
\underline{\psi}\left(x ; F_{i}\right) \equiv \psi_{i}(\underline{\theta} ;[x, \bar{\theta}])=\frac{\beta}{2} E\left\{\theta_{i} \mid \theta_{i}>x\right\}+\left(1-\frac{\beta}{2}\right) \underline{\theta}-E\left\{\theta_{j}\right\}
$$

Notice that if $\left(\mathrm{C}_{O}\right)$ holds strictly, then $\psi_{i}\left(\underline{\theta} ; \mathcal{S}_{i}\right)>\psi_{i}\left(\bar{\theta} ; \mathcal{S}_{i}\right)$ for any $\mathcal{S}_{i}$. Hence, there exists a $\widetilde{\theta}$, with $\widehat{\theta}_{i}<\widetilde{\theta}<\bar{\theta}$, such that $\psi_{i}\left(\widetilde{\theta} ; \mathcal{S}_{i}\right)=\psi_{i}\left(\underline{\theta} ; \mathcal{S}_{i}\right)$ for any $\mathcal{S}_{i}$. Take a distribution $\widetilde{F}_{i}$ such that $\left.\psi_{i}(\widetilde{\theta} ; \tilde{\theta}, \bar{\theta}]\right)=0 .{ }^{17}$ Clearly, for distributions $\widetilde{F}_{i}$ and $F_{j}$ there exists an equilibrium with $\mathcal{S}_{i}=[\widetilde{\theta}, \bar{\theta}]$ and $\mathcal{S}_{j}=\Theta$, since $\underline{\psi}\left(\widetilde{\theta}_{\tilde{\theta}} \widetilde{F}_{i}\right)=\widetilde{\psi}\left(\widetilde{\theta} ; \widetilde{F}_{i}\right)=0$.

Now take any distribution function $G_{i}$, with $E_{G_{i}}\left\{\theta_{i} \mid \theta_{i}>\widetilde{\theta}\right\} \leq E_{\widetilde{F}_{i}}\left\{\theta_{i} \mid \theta_{i}>\widetilde{\theta}\right\}$. For this distribution $\underline{\psi}\left(\widetilde{\theta} ; G_{i}\right) \leq 0<\underline{\psi}\left(\bar{\theta} ; G_{i}\right)$, where the first inequality follows from $\underline{\psi}\left(\widetilde{\theta} ; G_{i}\right) \leq \underline{\psi}\left(\widetilde{\theta} ; \widetilde{F}_{i}\right)=0$ and the second inequality follows from $\left(\mathrm{C}_{O}\right)$. Hence, there exists some $\theta_{o}$, with $\widetilde{\theta} \leq \theta_{o}<\bar{\theta}$, such that $\underline{\psi}\left(\theta_{o} ; G_{i}\right)=0$ and $\underline{\psi}\left(\theta ; G_{i}\right)>0$ for all $\theta>\theta_{o}$. Further,

$$
\begin{aligned}
\widetilde{\psi}\left(\theta_{o} ; G_{i}\right) & =\underline{\psi}\left(\theta_{o} ; G_{i}\right)+E\left\{\theta_{j}\right\}-\left(1-\frac{\beta}{2}\right) \underline{\theta}-\frac{\beta}{2} \theta_{o}-\left[1-F_{j}\left(\theta_{o}\right)\right]\left(E\left\{\theta_{j} \mid \theta_{j}>\theta_{o}\right\}-\theta_{o}\right) \\
& =E\left\{\theta_{j}\right\}-\left(1-\frac{\beta}{2}\right) \underline{\theta}-\frac{\beta}{2} \theta_{o}-\left[1-F_{j}\left(\theta_{o}\right)\right]\left(E\left\{\theta_{j} \mid \theta_{j}>\theta_{o}\right\}-\theta_{o}\right) \\
& \leq E\left\{\theta_{j}\right\}-\left(1-\frac{\beta}{2}\right) \underline{\theta}-\frac{\beta}{2} \widetilde{\theta}-\left[1-F_{j}(\widetilde{\theta})\right]\left(E\left\{\theta_{j} \mid \theta_{j}>\widetilde{\theta}\right\}-\widetilde{\theta}\right) \\
& =\underline{\psi}\left(\widetilde{\theta} ; \widetilde{F}_{i}\right)+E\left\{\theta_{j}\right\}-\left(1-\frac{\beta}{2}\right) \underline{\theta}-\frac{\beta}{2} \widetilde{\theta}-\left[1-F_{j}(\widetilde{\theta})\right]\left(E\left\{\theta_{j} \mid \theta_{j}>\widetilde{\theta}\right\}-\widetilde{\theta}\right) \\
& =\widetilde{\psi}\left(\widetilde{\theta} ; \widetilde{F}_{i}\right)=0
\end{aligned}
$$

where the inequality follows from the observation that the function $H(x) \equiv \frac{\beta}{2} x+[1-$ $\left.F_{j}(x)\right]\left(E\left\{\theta_{j} \mid \theta_{j}>x\right\}-x\right)$ is increasing in $x$ for all $x>\widehat{\theta}_{i}\left(\right.$ since $\left.H^{\prime}(x)=F_{j}(x)-\left(1-\frac{\beta}{2}\right)\right)$, and the fact that $\theta_{o} \geq \widetilde{\theta}$.

Also notice that $\widetilde{\psi}\left(\bar{\theta} ; G_{i}\right)=0$, and $\lim _{\theta \uparrow \bar{\theta}} d \widetilde{\psi}\left(\theta ; G_{i}\right) / d x<0$, since the first derivative of this function equals:

$$
\begin{aligned}
\frac{d \widetilde{\psi}\left(x ; G_{i}\right)}{d x} & =\frac{\beta}{2}\left(\frac{d}{d x} E\left\{\theta_{i} \mid \theta_{i}>x\right\}-1\right)-\frac{d}{d x}\left(\left[1-F_{j}(x)\right]\left(E\left\{\theta_{j} \mid \theta_{j} \geq x\right\}-x\right)\right) \\
& =\frac{\beta}{2}\left(\frac{g_{i}(x)}{1-G_{i}(x)}\left[E\left\{\theta_{i} \mid \theta_{i}>x\right\}-x\right]-1\right)+1-F_{j}(x)
\end{aligned}
$$

and its limit for $x$ approaching $\bar{\theta}$ equals:

$$
\lim _{x \uparrow \bar{\theta}} \frac{\widetilde{d \psi}\left(x ; G_{i}\right)}{d x}=\frac{\beta}{2}\left(g_{i}(\bar{\theta}) \lim _{x \uparrow \bar{\theta}} \frac{E\left\{\theta_{i} \mid \theta_{i}>x\right\}-x}{1-G_{i}(x)}-1\right)=\frac{-\beta}{4}
$$

${ }^{17}$ That is, $\widetilde{F}_{i}$ is such that: $\frac{\beta}{2} E_{\widetilde{F}_{i}}\left\{\theta_{i} \mid \theta_{i}>\widetilde{\theta}\right\}=\frac{\beta}{2} \widetilde{\theta}+\left[1-F_{j}(\widetilde{\theta})\right]\left(E\left\{\theta_{j} \mid \theta_{j}>\widetilde{\theta}\right\}-\widetilde{\theta}\right)$. 
since (by applying De L'Hospital rule)

$$
\begin{aligned}
\lim _{x \uparrow \bar{\theta}} \frac{E\left\{\theta_{i} \mid \theta_{i}>x\right\}-x}{1-G_{i}(x)} & =\lim _{x \uparrow \bar{\theta}} \frac{g_{i}(x) \frac{E\left\{\theta_{i} \mid \theta_{i}>x\right\}-x}{1-G_{i}(x)}-1}{-g_{i}(x)}=\frac{1}{g_{i}(\bar{\theta})}-\lim _{x \uparrow \bar{\theta}} \frac{E\left\{\theta_{i} \mid \theta_{i}>x\right\}-x}{1-G_{i}(x)} \\
& \Rightarrow \lim _{x \uparrow \bar{\theta}} \frac{E\left\{\theta_{i} \mid \theta_{i}>x\right\}-x}{1-G_{i}(x)}=\frac{1}{2 g_{i}(\bar{\theta})} .
\end{aligned}
$$

Hence, $\widetilde{\psi}\left(\theta_{i} ; G_{i}\right)>0$ for technologies $\theta_{i}$ close to $\bar{\theta}$.

In summary, $\widetilde{\psi}\left(\theta_{o} ; G_{i}\right) \leq 0<\widetilde{\psi}\left(\bar{\theta}-\varepsilon ; G_{i}\right)$ for small $\varepsilon>0$ and $\underline{\psi}\left(\theta ; G_{i}\right) \geq 0$ for all $\theta \geq \theta_{o}$. The intermediate value theorem implies that there exists an $h^{*}$, with $\theta_{o} \leq h^{*}<\bar{\theta}$, such that $\widetilde{\psi}\left(h^{*} ; G_{i}\right)=0$. Hence, $h^{*}$ satisfies the equilibrium conditions. Finally, Proposition 2 shows that firm $j$ keeps all $\theta_{j} \in \Theta$ secret in equilibrium.

\section{Proof of Proposition 8}

Under the proposition's conditions there should exist values $l^{*}$ and $h^{*}$, with $\underline{\theta}<l^{*}<$ $\widehat{\theta}_{i}<h^{*}<\bar{\theta}$, such that (i) $\psi_{i}\left(l^{*} ; \Theta \backslash\left[l^{*}, h^{*}\right]\right)=\psi_{i}\left(h^{*} ; \Theta \backslash\left[l^{*}, h^{*}\right]\right)$ and (ii) $\psi_{i}\left(h^{*} ; \Theta \backslash\left[l^{*}, h^{*}\right]\right)=$

0 . Now, if condition $\left(\mathrm{C}_{O}\right)$ holds strictly, then $\psi_{i}\left(\underline{\theta} ; \mathcal{S}_{i}\right)>\psi_{i}\left(\bar{\theta} ; \mathcal{S}_{i}\right)$ for any $\mathcal{S}_{i}$. The properties of $\psi_{i}$ imply the existence of $\widetilde{\theta} \in\left(\widehat{\theta}_{i}, \bar{\theta}\right)$ such that $\psi_{i}(\underline{\theta} ; \cdot)=\psi_{i}(\widetilde{\theta} ; \cdot)$.

First, condition (i) implicitly defines a decreasing, continuous function $\widetilde{l}:\left[\widehat{\theta}_{i}, \widetilde{\theta}\right] \rightarrow$ $\left[\underline{\theta}, \widehat{\theta}_{i}\right]$ with $\widetilde{l}\left(\widehat{\theta}_{i}\right)=\widehat{\theta}_{i}$ and $\widetilde{l}(\widetilde{\theta})=\underline{\theta}$.

Second, condition (ii) implicitly defines the continuous function $\widehat{l}:\left[\widehat{\theta}_{i}, \widetilde{\theta}\right] \rightarrow\left[\underline{\theta}, \widehat{\theta}_{i}\right]$. This follows from observing that (under symmetry) for any $h \in\left[\widehat{\theta}_{i}, \widetilde{\theta}\right]$ :

$$
\left.\psi_{i}\left(h ; \Theta \backslash \widehat{\theta}_{i}, h\right]\right) \leq 0 \leq \psi_{i}(h ; \Theta \backslash[\underline{\theta}, h]),
$$

where the first inequality follows from:

$$
\begin{aligned}
\left.\psi_{i}\left(h ; \Theta \backslash \widehat{\theta}_{i}, h\right]\right)= & \frac{\beta}{2}\left[E\left\{\theta_{i} \mid \theta_{i} \notin\left[\widehat{\theta}_{i}, h\right]\right\}-h\right]-\left[1-F_{j}(h)\right]\left(E\left\{\theta_{j} \mid \theta_{j}>h\right\}-h\right) \\
= & \frac{\beta}{2} \cdot \frac{F(\widehat{\theta})}{F(\widehat{\theta})+1-F(h)}(E\{\theta \mid \theta \leq \widehat{\theta}\}-h) \\
& +[1-F(h)]\left(\frac{\beta / 2}{F(\widehat{\theta})+1-F(h)}-1\right)(E\{\theta \mid \theta>h\}-h) \\
= & \frac{\beta}{2} \cdot \frac{-F(\widehat{\theta})}{F(\widehat{\theta})+1-F(h)}(h-E\{\theta \mid \theta \leq \widehat{\theta}\}) \\
& -[1-F(h)] \frac{1-\beta+1-F(h)}{F(\widehat{\theta})+1-F(h)}(E\{\theta \mid \theta>h\}-h) \leq 0,
\end{aligned}
$$


and the second inequality follows from:

$$
\begin{aligned}
\psi_{i}(h ; \Theta \backslash[\underline{\theta}, h]) & \left.=\frac{\beta}{2}\left[E\left\{\theta_{i} \mid \theta_{i}>h\right]\right\}-h\right]-\left[1-F_{j}(h)\right]\left(E\left\{\theta_{j} \mid \theta_{j}>h\right\}-h\right) \\
& \left.=\left[F(h)-\left(1-\frac{\beta}{2}\right)\right](E\{\theta \mid \theta>h]\}-h\right) \geq 0 .
\end{aligned}
$$

Application of the intermediate value theorem gives the existence of $\widehat{l}(h) \in\left[\underline{\theta}, \widehat{\theta}_{i}\right]$ such that $\left.\psi_{i}(h ; \Theta \backslash \widehat{l}(h), h]\right)=0$. In particular, the function $\widehat{l}$ has the extreme values: $\widehat{l}\left(\widehat{\theta}_{i}\right)=\underline{\theta}$ and $\underline{\theta}<\widehat{l}(\widetilde{\theta})<\widehat{\theta}_{i}$.

In summary, conditions (i) and (ii) define the continuous functions $\widetilde{l}, \widehat{l}:\left[\widehat{\theta}_{i}, \widetilde{\theta}\right] \rightarrow$ $\left[\underline{\theta}, \widehat{\theta}_{i}\right]$, with $\widetilde{l}\left(\widehat{\theta}_{i}\right)>\widehat{l}\left(\widehat{\theta}_{i}\right)$ and $\widetilde{l}(\widetilde{\theta})<\widehat{l}(\widetilde{\theta})$. Hence, the intermediate value theorem implies that there exists a $h^{*}$, with $\widehat{\theta}_{i}<h^{*}<\widetilde{\theta}$, such that $\widetilde{l}\left(h^{*}\right)=\widehat{l}\left(h^{*}\right)$. After defining $l^{*} \equiv \widetilde{l}\left(h^{*}\right)$, it follows that: $\psi_{i}\left(l^{*} ; \Theta \backslash\left[l^{*}, h^{*}\right]\right)=\psi_{i}\left(h^{*} ; \Theta \backslash\left[l^{*}, h^{*}\right]\right)=0$.

Finally, Proposition 2 shows that firm $j$ keeps all $\theta_{j} \in \Theta$ secret in equilibrium.

\section{Proof of Proposition 9}

Suppose that firms hold beliefs consistent with the technology-sharing strategy in the proposition, i.e., $\mathcal{S}_{i}=\left[\underline{\theta}, \widehat{\theta}_{i}-\varepsilon\right) \cup\left(\widehat{\theta}_{i}+\varepsilon, \bar{\theta}\right]$, and $\mathcal{S}_{j}=\Theta$ with $E\left(\theta_{j}\right)=\widehat{\theta}_{i}$. The perfect substitutability of goods and symmetry of firm $j$ 's technology distribution imply symmetry of $\psi_{i}$ around $\theta_{i}=\widehat{\theta}_{i}$, i.e., $\psi_{i}\left(\widehat{\theta}_{i}-\varepsilon ; \mathcal{S}_{i}\right)=\psi_{i}\left(\widehat{\theta}_{i}+\varepsilon ; \mathcal{S}_{i}\right)$ for all $\varepsilon \in\left[0, \frac{1}{2}(\bar{\theta}-\underline{\theta})\right]$ and any $\mathcal{S}_{i}$.

Define the continuous function $\widehat{\psi}:\left[0, \frac{1}{2}(\bar{\theta}-\underline{\theta})\right] \rightarrow \mathbb{R}$ as follows:

$$
\left.\widehat{\psi}(\varepsilon) \equiv \psi_{i}\left(\widehat{\theta}_{i}+\varepsilon ; \Theta \backslash \widehat{\theta}_{i}-\varepsilon, \widehat{\theta}_{i}+\varepsilon\right]\right) .
$$

Notice that an equilibrium condition for selective technology sharing by firm $i$ is: $\widehat{\psi}\left(\varepsilon^{*}\right)=0$ for $0<\varepsilon^{*}<\frac{1}{2}(\bar{\theta}-\underline{\theta})$. The violation of condition $\left(\mathrm{C}_{S}\right)$ implies that $\widehat{\psi}(0)>0$. Application of the De L'Hospital rule gives:

$$
\begin{aligned}
\lim _{\varepsilon \uparrow \frac{1}{2}(\bar{\theta}-\underline{\theta})} E\left\{\theta_{i} \mid \theta_{i}\right. & \left.\notin\left[\widehat{\theta}_{i}-\varepsilon, \widehat{\theta}_{i}+\varepsilon\right]\right\}=\lim _{\varepsilon \uparrow \frac{1}{2}(\bar{\theta}-\underline{\theta})} \frac{\int_{\underline{\theta}}^{\widehat{\theta}_{i}-\varepsilon} f_{i}(\theta) \theta d \theta+\int_{\widehat{\theta}_{i}+\varepsilon}^{\bar{\theta}_{i}} f_{i}(\theta) \theta d \theta}{F_{i}\left(\widehat{\theta}_{i}-\varepsilon\right)+1-F_{i}\left(\widehat{\theta}_{i}+\varepsilon\right)} \\
& =\lim _{\varepsilon \uparrow \frac{1}{2}(\bar{\theta}-\underline{\theta})} \frac{-f_{i}\left(\widehat{\theta}_{i}-\varepsilon\right)\left(\widehat{\theta}_{i}-\varepsilon\right)-f_{i}\left(\widehat{\theta}_{i}+\varepsilon\right)\left(\widehat{\theta}_{i}+\varepsilon\right)}{-f_{i}\left(\widehat{\theta}_{i}-\varepsilon\right)-f_{i}\left(\widehat{\theta}_{i}+\varepsilon\right)} \\
& =\frac{f_{i}(\underline{\theta})}{f_{i}(\underline{\theta})+f_{i}(\bar{\theta})} \underline{\theta}+\frac{f_{i}(\bar{\theta})}{f_{i}(\underline{\theta})+f_{i}(\bar{\theta})} \bar{\theta}<\bar{\theta} .
\end{aligned}
$$

Hence, $\lim _{\varepsilon \uparrow \frac{1}{2}(\bar{\theta}-\underline{\theta})} \widehat{\psi}(\varepsilon)<0$. The intermediate value theorem implies that there exists an $\varepsilon^{*}$, with $0<\varepsilon^{*}<\frac{1}{2}(\bar{\theta}-\underline{\theta})$, such that $\widehat{\psi}\left(\varepsilon^{*}\right)=0$.

Finally, Proposition 2 shows that firm $j$ keeps all $\theta_{j} \in \Theta$ secret in equilibrium. 


\section{References}

Allen, R.C. (1983) "Collective Invention", Journal of Economic Behavior and Organization 4, 1-24

Anton, J.J., And D.A. YaO (2003) "Patents, Invalidity, and the Strategic Transmission of Enabling Information", Journal of Economics 85 Management Strategy 12, $151-78$

Anton, J.J., And D.A. YaO (2004) "Little Patents and Big Secrets: Managing Intellectual Property", RAND Journal of Economics 35, 1-22

Arundel, A. (2001) "The Relative Effectiveness of Patents and Secrecy for Appropriation", Research Policy 30, 611-624

Blatter, M. And A. Niedermayer (2008) "Informational Hold-Up, Disclosure Policy, and Career Concerns on the Example of Open Source Software Development", Working Paper nr. 08-06, NET Institute

Bonrd, O. (2009) "Competition and Disclosure", Journal of Industrial Economics $57,197-213$

Cohen, W.M., Nelson, R.R. And Walsh, J.P. (2000) "Protecting Their Intellectual Assets: Appropriability Conditions and Why U.S. Manufacturing Firms Patent (or Not)", NBER Working Paper nr. 7552

Enchoua, D. And Y. Lefouili (2006) "Choosing Intellectual Protection: Imitation, Patent Strength and Licensing", Working Paper nr. 1715, CESifo, Munich

GaL-Or, E. (1986) "Information Transmission - Cournot and Bertrand Equilibria", Review of Economic Studies 53, 85-92

GILL, D. (2008) "Strategic Disclosure of Intermediate Research Results", Journal of Economics \& Management Strategy 17, 733-758

Harhoff, D., Henkel, J. and E. von Hippel (2003) "Profiting from Voluntary Information Spillovers: How Users Benefit by Freely Revealing Their Innovations", Research Policy 32, 1753-1769

Henkel, J. And M. Tins (2004) "Munich/MIT Survey: Development of Embedded Linux", Working Paper, INNO-TEC, University of Munich 
Jansen, J. (2006) "The Effects of Disclosure Regulation of an Innovative Firm", in J.P. Choi (ed.) Recent Developments in Antitrust: Theory and Evidence, Cambridge MA: MIT Press, pp. 265-291

Jansen, J. (2011) "On Competition and the Strategic Management of Intellectual Property in Oligopoly", Journal of Economics 83 Management Strategy 20, 1043-1072 Jansen, J. (2010) "Something Big (or Small) Is Gonna Happen: Strategic Information Disclosure in Contests", Working Paper, Max Planck Institute, Bonn

Leppämäki, M. And M. Mustonen (2009) "Skill Signaling with Product Market Externality", Economic Journal 119, 1130-1142

Lerner, J. And J. Tirole (2002) "Some Simple Economics of Open Source", Journal of Industrial Economics 50, 197-234

Levin, R., Klevorick, A., Nelson, R.R. and Winter, S.G. (1987) "Appropriating the Returns from Industrial R\&D", Brookings Papers on Economic Activity, $783-820$

Llanes, G. and R. De Elejalde (2009) "Industry Equilibrium with Open Source and Proprietary Firms", Working Paper nr. 09-149, Harvard Business School

Maurer, S.M. and S. Scotchmer (2006) "Open Source Software: The New Intellectual Property Paradigm", Working Paper nr. 12148, NBER

Milgrom, P.R. And J. Roberts (1986) "Relying on the Information of Interested Parties", RAND Journal of Economics 17, 18-32

Moody, G. (2001) Rebel Code: Linux and the Open Source Revolution, London, UK: Allen Lane, The Penguin Press

Okuno-Fujiwara, M., Postlewaite A. and K. Suzumura (1990) "Strategic Information Revelation", Review of Economic Studies 57, 25-47

Shapiro, C. (1986) "Exchange of Cost Information in Oligopoly", Review of Economic Studies 53, 433-446

Spiegel, Y. (2009) "The Incentive to Participate in Open Source Projects: A Signaling Approach", Working Paper, Tel Aviv University

Sun, M. (2011) "Disclosing Multiple Product Attributes", Journal of Economics $\mathcal{E}^{3}$ Management Strategy 20, 195-224

Von Hippel, E. (2005) Democratizing Innovation, Cambridge, MA: MIT Press. 